\title{
Chapter 1 \\ Ceramic Casting Technologies for Fine and Coarse Grained TRIP-Matrix-Composites
}

\author{
Claudia Heuer, Marie Oppelt and Christos G. Aneziris
}

\begin{abstract}
The present contribution focuses on the development of composite materials using innovative ceramic casting technologies. Within this work different processing routes, the relevance of their process parameters as well as the resulting mechanical and microstructural characteristics are discussed. The successfully developed TRIP-matrix foams as well as full beads reinforced with 5 and $10 \mathrm{vol}$. $\%$ zirconia achieve higher compressive strengths and energy absorption during deformation in comparison to the pure metal materials as references. The functionally graded beads allowed a compression of up to $20 \%$ with corresponding specific energy absorption of $10.7 \mathrm{~kJ} / \mathrm{kg}$. In a further approach, metal-matrix composites have been generated via paper-manufacturing technology. The partial replacement of cellulose fibers by commercially available zirconia fibers resulted in fiber reinforced TRIP-matrix composites with an increased tensile strength of approx. $33 \%$ as compared to the pure metal material as reference. Large-size ceramic matrix composites with high potential for applications requiring sufficient wear and thermal shock resistance have been successfully prepared via pressure slip casting. The last topic is concerned with the development of yttria-stabilized zirconia fibers with a tailored phase composition (monoclinic-tetragonal-cubic) via electrospinning.
\end{abstract}

\subsection{Introduction}

The increasing technological demand within the last decades led to the development of composites significantly enlarging the application field of conventional materials. The research efforts are not only concerned with innovative material systems but also with novel fabrication technologies, always with the aim to create composites with

C. Heuer $(\varangle) \cdot$ M. Oppelt · C. G. Aneziris

Institute of Ceramic, Glass and Construction Materials, Technische Universität Bergakademie

Freiberg, Agricolastr. 17, 09599 Freiberg, Germany

e-mail: claudia.heuer@ikgb.tu-freiberg.de 

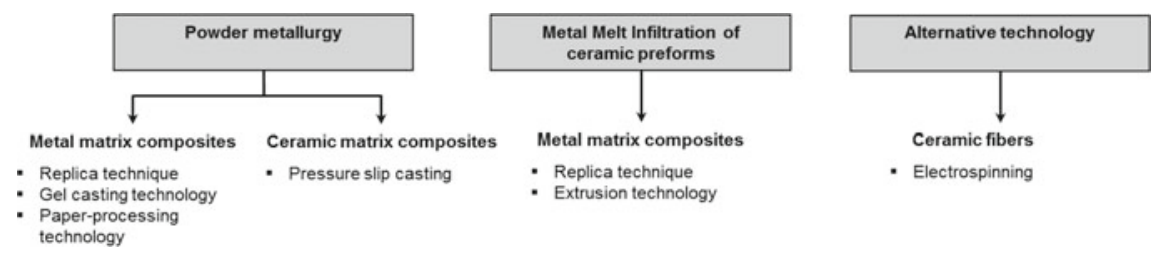

Fig. 1.1 Flowchart of the applied casting technologies

superior mechanical, thermal, thermo-mechanical, wear- and damping-related properties. Within the frame of the Collaborative Research Center 799-TRIP-matrixcomposites based on metastable austenitic steel and magnesia partially stabilized zirconia are of interest. The combination of metastable austenitic steel with transformation induced plasticity with magnesia partially stabilized zirconia is advantageous in terms of high strength and specific energy absorption. $[1,2]$ Both materials exhibit a martensitic phase transformation triggered upon exposure to external stresses.

The present work focuses on the development of metal matrix and ceramic matrix composites using innovative casting technologies that are typically employed for the fabrication of ceramic components (Fig. 1.1). A main emphasis is the development of metal matrix composites $(M M C)$ using the replica technique, the gel casting and the paper technology. Furthermore, the infiltration of ceramic preforms by TRIPsteel melts was studied. The preforms are prepared using the replica technique or extrusion technology. Ceramic matrix composites $(C M C)$ are generated using the pressure slip casting technology. In addition to that electrospinning has been applied for the development of zirconia fibers with tailored phase compositions. Within the present work the different processing routes, the relevance of their process parameters and the resulting microstructural and mechanical characteristics will be illustrated and discussed.

\subsection{Experimental Details}

This work is divided into four main parts; the first one deals with the development of TRIP-matrix composites by replica technique, gel casting and paper-processing technology. The second part concerns the metal melt infiltration of ceramic preforms (obtained via replica technique and extrusion). The development of ceramic matrix composites by pressure slip casting was the third part of the study. Finally, an alternative technology for the fabrication of zirconia fibers is introduced. The following section will provide information on the raw materials as well as on the methods of characterization. The sample preparation for the mentioned technologies will be illustrated. 


\subsubsection{Raw Materials}

\subsubsection{Magnesia Partially Stabilized Zirconia}

Within the present work three different types of fused cast magnesia partially stabilized zirconia (Saint Gobain, USA) have been used. The zirconia powders are hereinafter referred to as Mg-PSZ (fine) with $d_{50}=1.3 \mu \mathrm{m}, \mathrm{Mg}$-PSZ (coarse) with $d_{50}=3.0 \mu \mathrm{m}$ and Mg-PSZ (new) with $d_{50}=4.3 \mu \mathrm{m}$. The chemical compositions of the different Mg-PSZ powders are summarized in Table 1.1.

\subsubsection{Austenitic Stainless TRIP-Steel}

Three different types of austenitic stainless steel powder (TLS Technik Bitterfeld, Germany) have been utilized in the present work. The commercially available AISI 304 (X5CrMnNi18-1-10) with a mean particle size of $33 \mu \mathrm{m}$ has been employed for the development of MMCs via replica technique. The other steel powders following referred to as X8CrMnNi16-7-3 $\left(d_{50}=21.9 \mu \mathrm{m}\right)$ and $\mathrm{X} 3 \mathrm{CrMnNi}$ 7-6 $\left(d_{50}=25 \mu \mathrm{m}\right)$ had a substantially higher manganese content, which partially replaced nickel. The true densities were determined to be $7.83 \mathrm{~g} / \mathrm{cm}^{3}$ (X5CrMnNi181-10), $7.78 \mathrm{~g} / \mathrm{cm}^{3}$ (X8CrMnNi16-7-3) and $7.83 \mathrm{~g} / \mathrm{cm}^{3}$ (X3CrMnNi16-7-6), respectively. During the investigations several steel batches have been used having minor differences in their chemical composition, see Table 1.2.

\subsubsection{Alumina}

Calcined and reactive alumina powders were used for the pressure slip casting of alumina based composites. The fine and coarse grained powders had mean particle

Table 1.1 Chemical compositions of the zirconia powders in wt.\%

\begin{tabular}{l|l|l|l|l|l|l}
\hline & $\mathrm{ZrO}_{2}$ & $\mathrm{MgO}$ & $\mathrm{HfO}_{2}$ & $\mathrm{SiO}_{2}$ & $\mathrm{Al}_{2} \mathrm{O}_{3}$ & $\mathrm{TiO}_{2}$ \\
\hline Mg-PSZ (fine) & Bal. & 3.37 & 1.73 & 2.43 & 0.63 & 0.14 \\
\hline Mg-PSZ (coarse) & Bal. & 2.82 & 1.74 & 0.41 & 0.38 & 0.13 \\
\hline Mg-PSZ (new) & Bal. & 1.85 & 1.85 & 0.10 & 1.58 & 0.13 \\
\hline
\end{tabular}

Table 1.2 Chemical compositions of the steel powders in wt.\%

\begin{tabular}{l|l|l|l|l|l|l|l}
\hline & $\mathrm{Fe}$ & $\mathrm{Cr}$ & $\mathrm{Mn}$ & $\mathrm{Ni}$ & $\mathrm{C}$ & $\mathrm{Si}$ & $\mathrm{S}$ \\
\hline PMX5CrMnNi18-1-10 & Bal. & $17.50-18.10$ & $1.13-1.30$ & $7.8-8.74$ & $0.03-0.05$ & $0.40-0.55$ & $0.01-0.02$ \\
\hline PMX8CrMnNi16-7-3 & Bal. & $15.60-16.70$ & $6.02-7.14$ & $3.04-3.50$ & $0.04-0.08$ & $0.80-0.93$ & $0.00-0.01$ \\
\hline PMX3CrMnNi16-7-6 & Bal. & $15.90-16.30$ & $7.10-7.20$ & $6.60-6.90$ & $0.02-0.03$ & $1.00-1.16$ & 0.01 \\
\hline
\end{tabular}


sizes ranging from $0.2 \mu \mathrm{m}$ to $3 \mathrm{~mm}$ and were provided by Almatis (Ludwigshafen, Germany) and Martinswerke (Bergheim, Germany), respectively.

\subsubsection{Raw Materials for Electrospinning}

For the development of nanofibers via electrospinning high purity zirconyl chloride octahydrate (Sigma Aldrich Steinheim, Germany), yttrium (III) nitrate hexahydrate (Sigma Aldrich Steinheim, Germany) and magnesium nitrate hexahydrate served as precursor materials for the synthesis of zirconia fibers stabilized with 3 mol. $\%$ yttria and $8 \mathrm{~mol} \%$ magnesia, respectively. Granular polyvinylpyrrolidone (PVP) with an average $M_{w}$ of $1.3 \times 10^{6} \mathrm{~g} / \mathrm{mol}$ (Sigma Aldrich Steinheim, Germany) was employed as polymeric component. The starting materials were dissolved in deionized water and ethanol with a purity of $\geq 99.8 \%$ (Carl Roth Karlsruhe, Germany), respectively. Triton X (Sigma Aldrich Steinheim, Germany) was used as non-ionic surfactant.

\subsubsection{Sample Preparation}

\subsubsection{Development of TRIP-Matrix Composites via Powder Metallurgy}

Aneziris et al. [3] produced open cell foam structures via replica technique from $30 \mathrm{ppi}$ (pores per inch) polyurethane foams with dimensions of $50 \times 50 \times 20 \mathrm{~mm}^{3}$. Two different compositions based on 100 vol.\% steel powder (0Z) and 90 vol. $\%$ steel powder and 10 vol.\% Mg-PSZ powders (10Z) were evaluated. The composition of the impregnation slurries is shown in Table 1.3. The polyurethane foams were fully immersed in the slurry, afterwards the excess slurry was removed with the aid of a manual roller mill. After this first impregnation step the filters were dried at $90{ }^{\circ} \mathrm{C}$ for $1 \mathrm{~h}$. In a second coating step the dried foams were sprayed with a spraying slurry based on the same composition as the impregnation slurry, see Table 1.3. The spraying slurry was prepared using a ViscoJet stirrer system. The spray coating was performed with the aid of a SATAjet B spraying gun 1.0 E nozzle type. In a further version, a dense coating (hereafter indicated by the letter "J" in the slurry compositions) of approx. $1.5 \mathrm{~mm}$ thickness was applied on the $50 \times 20 \mathrm{~mm}^{2}$ side surfaces for both slurry compositions. The corresponding samples were designated to as $0 \mathrm{ZJ}$ and $10 \mathrm{ZJ}$. After drying the samples have been sintered at $1350{ }^{\circ} \mathrm{C}$ for $2 \mathrm{~h}$ in an electrical furnace Linn HT $1600 \mathrm{GT}$ Vac with $\mathrm{MoSi}_{2}$-heating elements in 99.9.\% argon atmosphere.

Full and hollow TRIP-matrix composite beads were prepared with the aid of gel casting. The composition of the slurries with a powder to water ratio of 70:30 is given in Table 1.4. For the generation of full beads calcium chloride was chosen as hardener and the prepared aqueous hardener solution contained 0.8 wt. $\%$ calcium chloride [4]. For the fabrication of hollow beads calcium hydroxide had to be applied 
1 Ceramic Casting Technologies for Fine and Coarse Grained ...

Table 1.3 Composition of the slurries for replica technique in wt.\% [3]

\begin{tabular}{|c|c|c|c|c|}
\hline & Type & Supplier & $0 Z$ & $10 Z$ \\
\hline \multicolumn{5}{|l|}{ Raw materials } \\
\hline $\begin{array}{l}\text { Austenitic TRIP-steel } \\
\text { powder }\end{array}$ & PMX5CrMnNi18-1-10 & TLS Technik, GER & 94.99 & 87.67 \\
\hline $\mathrm{ZrO}_{2}$ & Mg-PSZ (coarse) & Saint Gobain, USA & - & 7.32 \\
\hline \multicolumn{5}{|l|}{ Additives } \\
\hline Antifoam & Axilat DF $581 \mathrm{~B}$ & C.H. Erbslöh, GER & 0.11 & 0.11 \\
\hline Surfactant & PPG P400 & Sigma-Aldrich, GER & 0.55 & 0.55 \\
\hline Binder & Optapix PAF 35 & $\begin{array}{l}\text { Zschimmer and } \\
\text { Schwarz, GER }\end{array}$ & 1.66 & 1.66 \\
\hline Dispersant & Darvan C & R.T. Vanderbilt, USA & 0.47 & 0.47 \\
\hline Binder & Ligninsulfonate T11B & Otto Dille, GER & 1.66 & 1.66 \\
\hline \multirow[t]{2}{*}{ Stabilizer } & Axilat RH 50 MD & C.H. Erbslöh, GER & 0.56 & 0.56 \\
\hline & & Total & 100 & 100 \\
\hline \multicolumn{5}{|l|}{ Dispersing fluid } \\
\hline Water (coating) & Deionized & & 9.5 & 9.5 \\
\hline Water (spraying) & Deionized & & 19.2 & 19.2 \\
\hline
\end{tabular}

Table 1.4 Composition of the slurries used for gel casting in wt.\% [7]

\begin{tabular}{|c|c|c|c|c|c|c|c|}
\hline & Type & Supplier & $0 Z$ & $5 Z$ & $10 Z$ & $20 Z$ & $100 Z$ \\
\hline \multicolumn{8}{|c|}{ Raw materials } \\
\hline $\begin{array}{l}\text { Austenitic } \\
\text { TRIP-steel } \\
\text { powder }\end{array}$ & $\begin{array}{l}\text { PMX8CrMnNi } \\
16-7-3\end{array}$ & TLS, GER & 68.47 & 65.00 & 61.83 & 54.62 & - \\
\hline $\mathrm{ZrO}_{2}$ & $\begin{array}{l}\text { Mg-PSZ } \\
\text { (coarse) }\end{array}$ & $\begin{array}{l}\text { Saint Gobain, } \\
\text { USA }\end{array}$ & - & 3.47 & 6.64 & 13.85 & 68.47 \\
\hline \multicolumn{8}{|l|}{ Additives } \\
\hline $\begin{array}{l}\text { Sodium } \\
\text { alginate }\end{array}$ & FD 175 & $\begin{array}{l}\text { C.E. Roeper, } \\
\text { GER }\end{array}$ & 0.42 & 0.42 & 0.42 & 0.42 & 0.42 \\
\hline Plasticizer & Darvan C & $\begin{array}{l}\text { R.T. } \\
\text { Vanderbilt, } \\
\text { USA }\end{array}$ & 0.69 & 0.69 & 0.69 & 0.69 & 0.69 \\
\hline Stabilizer & KM2000 & $\begin{array}{l}\text { Zschimmer and } \\
\text { Schwarz, GER }\end{array}$ & 0.42 & 0.42 & 0.42 & 0.42 & 0.42 \\
\hline \multicolumn{8}{|c|}{ Dispersing fluid } \\
\hline Water & Deionized & & 30 & 30 & 30 & 30 & 30 \\
\hline
\end{tabular}


Table 1.5 Composition of the feedstocks excluding water in vol.\%

\begin{tabular}{|c|c|c|c|c|c|c|}
\hline & Type & Supplier & $0 \mathrm{Z}$ & $10 \mathrm{Z}$ & $3 Z F$ & $6 \mathrm{ZF}$ \\
\hline \multicolumn{7}{|l|}{ Raw materials } \\
\hline $\begin{array}{l}\text { Austenitic TRIP- } \\
\text { steel powder }\end{array}$ & $\begin{array}{l}\text { PMX3CrMnNi } \\
16-7-6\end{array}$ & TLS Technik, GER & 78.5 & 71.2 & 78.5 & 78.5 \\
\hline $\mathrm{ZrO}_{2}$ & Mg-PSZ (new) & Saint Gobain, USA & - & 7.9 & - & - \\
\hline $\mathrm{ZrO}_{2}$-Fibers & Yttria-stabilized & Final GmbH, GER & - & - & 2.5 & 5.0 \\
\hline Cellulose & - & $\begin{array}{l}\text { Zellstoff Pöls AG, } \\
\text { AT }\end{array}$ & 14.5 & 14.1 & 12.0 & 9.5 \\
\hline \multicolumn{7}{|l|}{ Additives } \\
\hline Starch & - & $\begin{array}{l}\text { Südstärke Chemie, } \\
\text { GER }\end{array}$ & 7.0 & 7.0 & 7.0 & 7.0 \\
\hline
\end{tabular}

as hardener in a $1.0 \mathrm{wt} . \%$ aqueous hardener solution [5]. The prepared slurries were added dropwise into the hardener solutions and thus solidification took place. Additionally, functionally graded beads were prepared as described by Oppelt et al. [6]. The wet green beads were removed from the hardener solution and dried for $24 \mathrm{~h}$ at $40{ }^{\circ} \mathrm{C}$. After debinding, the beads were sintered in an inert atmosphere (Ar 5.0) in an XGraphit furnace (XERION Ofentechnik Freiberg, Germany) with a heating rate of $1 \mathrm{~K} / \mathrm{min}$ up to $660{ }^{\circ} \mathrm{C}$ with a dwelling time of $60 \mathrm{~min}$ at $660{ }^{\circ} \mathrm{C}$, followed by a heating rate of $5 \mathrm{~K} / \mathrm{min}$ up to $1350{ }^{\circ} \mathrm{C}$ and a dwelling time of $120 \mathrm{~min}$ at $1350{ }^{\circ} \mathrm{C}$. The cooling rate was $5 \mathrm{~K} / \mathrm{min}$.

The development of TRIP-matrix composites via paper-manufacturing technology comprised several steps. The pulp suspension contained $0.27 \mathrm{wt} . \%$ cellulose fibers and $0.01 \mathrm{wt} . \%$ cationic starch. In order to obtain the feedstock, a $90 \mathrm{wt} . \%$ aqueous suspension containing stainless steel, magnesia partially stabilized zirconia, and 0.17 wt. \% anionic starch were added to the pulp suspension. In context of the development the cellulose pulp fibers have been partially replaced ( 2.5 and 5 vol.\%) by commercially available yttria-stabilized zirconia fibers. Thus, fiber reinforced TRIP-matrix composites were prepared. The composition of the feedstock excluding water is given in Table 1.5. Square paper sheets with $200 \mathrm{~mm}$ in length were then formed on a laboratory sheet-forming device. The green sheets were stepwise dried starting from $40{ }^{\circ} \mathrm{C}$ up to $110^{\circ} \mathrm{C}$ within $24 \mathrm{~h}$. Subsequently, the dried paper sheets were calendered on a rolling mill applying a line load of $30 \mathrm{kN} / \mathrm{mm}$ at a roller speed of $0.1 \mathrm{~m} / \mathrm{s}$. The calendered sheets were thermally treated using an debinding and sintering process developed by Wenzel [8].

\subsubsection{Development of TRIP-Matrix Composites via Metal Melt Infiltration of Ceramic Preforms}

Open cell foam structures based on magnesia-partially stabilized zirconia for the infiltration with TRIP-steel melts were prepared using the replica technique. The 
fabrication of these foam structures comprises two coating steps as mentioned before. The impregnation of the polyurethane foams was done according to the description in Sect. 1.2.2.1. The spray coating procedure was modified and performed airstream assisted. The impregnated foam was therefore placed into a tubular sample holder connected to a vacuum unit. The distance between sample holder and spraying gun was set to $27 \mathrm{~cm}$ for all experiments; the pressure of the compressed air was maintained at $0.3 \mathrm{MPa}$. The mass flow of the slurry was set to $80 \mathrm{~g} / \mathrm{min}$ and the foams were sprayed for $8 \mathrm{~s}$. A detailed description of the experimental setup is given elsewhere [9]. The spraying slurries were prepared with different powder to water ratios. The spraying slurries contained $40 \mathrm{wt} . \%$ water, $45 \mathrm{wt} . \%$ and $55 \mathrm{wt} . \%$ water, respectively After coating, the foams were dried at $110{ }^{\circ} \mathrm{C}$. Debinding and sintering was performed in an oxidizing atmosphere. Debinding took place at $500{ }^{\circ} \mathrm{C}$ with a heating rate of $1 \mathrm{~K} / \mathrm{min}$ and a holding time of $60 \mathrm{~min}$. Sintering was performed at $1600{ }^{\circ} \mathrm{C}$ with a heating rate of $5 \mathrm{~K} / \mathrm{min}$ and a dwell time of $120 \mathrm{~min}$.

The extrusion technology was applied as a further option for the fabrication of porous ceramic preforms, honeycombs and randomly arranged spaghetti-filters, which have been casted with TRIP-steel melt. The preparation and the extrusion of the different plastic feeds are described in detail by Wenzel and Aneziris [10] and Schärfl et al. [11]. Honeycomb specimens with $196 \mathrm{cpsi}$ (channels per square inch) and a wall thickness of $250 \mu \mathrm{m}$ as well as randomly arranged full strand-spaghettifilters with a strand diameter of $1 \mathrm{~mm}$ have been prepared. Both extruded ceramic preform types were sintered in an electrical heating furnace with $\mathrm{MoSi}_{2}$-heating elements in oxidizing atmosphere. The heating rate was $1 \mathrm{~K} / \mathrm{min}$ to $350{ }^{\circ} \mathrm{C}$ with a holding time of $90 \mathrm{~min}$ and then $3 \mathrm{~K} / \mathrm{min}$ to $1650{ }^{\circ} \mathrm{C}$ with a holding time of $120 \mathrm{~min}$.

Subsequently, the ceramic preforms were infiltrated by a Cast X5CrMnNi16-7-7 steel melt in order to obtain bulk TRIP-matrix composites. Therefore, the preforms were preheated to $1000{ }^{\circ} \mathrm{C}$ with a holding time of $10 \mathrm{~h}$ and then placed in an unheated sodium silicate bonded $\mathrm{SiO}_{2}$ sand mold. The samples were fixed to the bottom of the mold. The experimental setup is discussed in detail by Weider and Eigenfeld [12]. The steel casting took place with a temperature of $1600{ }^{\circ} \mathrm{C}$ in oxidizing atmosphere. A constant height of the feeder was guaranteed due to an inclined drainage for excess steel.

\subsubsection{Development of Ceramic Matrix Composites via Pressure Slip Casting}

Slip preparation comprised several steps, starting with the addition of the organic additives Welan Gum and Konjac flour in deionized water for 10 min using a Heidolph homogenizer DIAX 600 (Heidolph Instruments Schwabach, Germany). Subsequently, the solid fractions and the additive-water mixture have been homogenized for $15 \mathrm{~min}$ in an intensive laboratory mixer RV02 (Maschinenfabrik Gustav Eirich Hardheim, Germany) to obtain the slurries. Casting was performed in a modified industrial pressure slip casting device DGM80D (Dorst Technology Kochel am See, Germany). The suspension was pumped from a receiver tank into a polyurethane 
mould $\left(200 \times 200 \times 38 \mathrm{~mm}^{3}\right)$ at a pressure of $0.1-0.15 \mathrm{MPa}$. The pressure was then increased to $2 \mathrm{MPa}$ and held constant for the whole casting time of $25 \mathrm{~min}$. Afterwards, the pressure was released and the green specimens have been demoulded. The casted bodies were subsequently dried up to $110{ }^{\circ} \mathrm{C}$. Debinding took place in an oxidizing atmosphere with a heating rate of $1 \mathrm{~K} / \mathrm{min}$ up to $400{ }^{\circ} \mathrm{C}$ and a dwelling time of $90 \mathrm{~min}$ at $400{ }^{\circ} \mathrm{C}$. Sintering was conducted in a XGraphit furnace (XERION Ofentechnik Freiberg, Germany) with a heating rate of $5 \mathrm{~K} / \mathrm{min}$ to $1450{ }^{\circ} \mathrm{C}$ and a holding time of $120 \mathrm{~min}$ and an argon flow rate of $2.5 \mathrm{l} / \mathrm{min}$ at an excess pressure of 5 mbar.

\subsubsection{Development of Ceramic Fibers Using Electrospinning}

With the aid of the electrospinning technology yttria-stabilized zirconia fibers have been developed. First, a 18 wt.\% precursor solution was prepared by dissolving $\mathrm{ZrOCl}_{2} \cdot 8 \mathrm{H}_{2} \mathrm{O}$ and $\mathrm{Y}\left(\mathrm{NO}_{3}\right)_{3} \cdot 6 \mathrm{H}_{2} \mathrm{O}$ in deionized water in a ratio that corresponds to the final composition $\mathrm{ZrO}_{2}-3 \mathrm{~mol} \% \mathrm{Y}_{2} \mathrm{O}_{3}$. In a second step, a $7 \mathrm{wt}$. \% polymeric solution was obtained by dissolving the granular PVP in ethanol. The polymeric solution was stirred on a magnetic stirrer at $500 \mathrm{rpm}$ for $30 \mathrm{~min}$. The polymeric solution was then poured stepwise into the precursor solution with a 3:1 weight ratio. Finally, 0.5 wt. $\%$ Triton $\mathrm{X}$ was added and the stock solution was further stirred at $250 \mathrm{rpm}$ for $240 \mathrm{~min}$. The electrospinning was conducted using an electrospinning device NE 300 (Inovenso Istanbul, Turkey) with a bottom-up configuration and a 4nozzles feeding unit, each nozzle having an inner diameter of $0.8 \mathrm{~mm}$. The processing temperature and relative humidity were kept constant at $23^{\circ} \mathrm{C}$ and $40 \%$, respectively. The stock solution was fed at $3.5 \mathrm{ml} / \mathrm{h}$ with a high precision syringe pump (New Era Pump Systems Farmingdale, USA). The electrospinning was carried out at a voltage of $24 \mathrm{kV}$ using a DC power supply at a distance between needle tip and collector of $75 \mathrm{~mm}$. The fibers were collected on a drum that was covered with alumina foil and which was rotating at $300 \mathrm{rpm}$. The sintering of the nanofibers was performed at different temperature of $700,1100,1350$ and $1650{ }^{\circ} \mathrm{C}$.

\subsubsection{Characterization of the Composite Materials}

\subsubsection{Rheological Characterization of the Slurries}

The rheological properties of the slurries developed for the gel-casting of metal beads as well as for the impregnation and spraying of polyurethane foams were investigated using a rotational viscometer Haake RheoStress 150 (ThermoHaake Karlsruhe, Germany). The rheological experiments were carried out under shear control. For the gel-casting the slurries were investigated with a given shear rate of $1-500 \mathrm{~s}^{-1}$ in $150 \mathrm{~s}$. After a holding time of $100 \mathrm{~s}$ at $500 \mathrm{~s}^{-1}$ the shear rate was decreased again. The slurries for the impregnation of the polyurethane foams were 
investigated with given shear rates of $1-200 \mathrm{~s}^{-1}$ or $1000 \mathrm{~s}^{-1}$ in $300 \mathrm{~s}$. After a holding time of $60 \mathrm{~s}$ at $200 \mathrm{~s}^{-1}$ and $1000 \mathrm{~s}^{-1}$ respectively it was stepwise decreased to $1 \mathrm{~s}^{-1}$.

\subsubsection{Thermal Analysis}

Highly relevant aspects for the development of composite materials containing TRIPsteel are investigations on the thermal decomposition behavior of the temporary additives. Differential scanning calorimetry (DSC) combined with thermo-gravimetric measurements (TG) were performed using a STA 409 (NETZSCH Waldkraiburg, Germany). During decomposition experiments the DSC/TG device was flushed with synthetic air. For the fabrication of metal beads using gel-casting the decomposition behavior of sodium alginate was of fundamental importance. The chosen heating rate was $10 \mathrm{~K} / \mathrm{min}$ to $1000{ }^{\circ} \mathrm{C}$. For the paper-derived TRIP-matrix composites the decomposition behavior of the cellulose pulp fibers was investigated up to $800{ }^{\circ} \mathrm{C}$ with a heating rate of $1 \mathrm{~K} / \mathrm{min}$.

\subsubsection{Physical Properties}

The linear shrinkage after sintering was calculated according to DIN EN 993-10. For the full and hollow metal beads, the pressure slip-casted ceramic matrix composites as well as for the zirconia preforms obtained by extrusion the open porosity, the pore size distribution as well as the bulk density were investigated with the aid of a mercury porosimeter (PASCAL series, Porotec Hofheim am Taunus, Germany). The thickness of the paper-derived TRIP-matrix composites was determined after processing and calendering at five different positions for each sheet using a digital vernier caliper and an analogue dial gauge. The bulk density was determined from weight and volume measurements before and after sintering. The volume of the samples was determined by displacement in mercury volume meter. The theoretical density of the composite mixtures was calculated according to the rule of mixture using the density of the initial powders as measured by helium pycnometry.

\subsubsection{Mechanical Properties}

The mechanical properties of the different composites were determined. Compressive deformation tests have been performed on a $500 \mathrm{kN}$ servohydraulic testing device type MTS 880 (MTS Systems Eden Prairie, USA) with a displacement rate of $0.016 \mathrm{~mm} / \mathrm{s}$ for the TRIP-matrix composite foams prepared via replica technique. For the hollow and full TRIP-matrix composite beads the compressive deformation strength was measured with a testing machine TT 2420 (TIRA Schalkau, Germany) arranged with a measuring equipment for single granules. 20 beads of each composition have been tested to failure with a displacement rate of $0.05 \mathrm{~mm} / \mathrm{s}$. In case of functionally graded beads the compressive strength was determined with a measuring 
device for single granules and a displacement rate of $0.002 \mathrm{~mm} / \mathrm{s}$ with a load cell of $10 \mathrm{kN}$. For these metal matrix composites the specific energy absorption (SEA) was calculated according to (1.1) and (1.2). SEA $\mathrm{V}_{\mathrm{V}}$ is defined as specific energy absorption per volume $(V)$ unit, $\mathrm{SEA}_{m}$ refers to mass $(m)$ unit, respectively.

$$
\begin{gathered}
\operatorname{SEA}_{V}=\frac{W}{V} \quad \operatorname{SEA}_{m}=\frac{W}{m} \\
W=\int_{0}^{S_{b}} P \mathrm{~d} S
\end{gathered}
$$

$W$ is the total energy absorbed during sample deformation, $P$ the load, $S$ the displacement, and $S_{b}$ is the strain at end of experiment according to Jacob et al. [13].

The tensile strength of the as-fabricated and calendered paper-derived materials was determined according to DIN EN ISO 1924-2 on a servohydraulic testing machine TT 28100 (TIRA Schalkau, Germany). The clamping length was $65 \mathrm{~mm}$ and the sample width was $10 \mathrm{~mm}$. The crosshead speed for the as-fabricated samples was $5 \mathrm{~mm} / \mathrm{min}$, and for the calendered samples $3 \mathrm{~mm} / \mathrm{min}$. Different crosshead speeds had to be applied in order to ensure sample fracture within 5-30 s as given by the standard.

The tensile strength of the paper-derived TRIP-matrix composites after sintering was determined according to DIN EN ISO 6892-1. It was investigated on as-sintered samples with the following dimensions (before sintering): $l_{0}=150 \mathrm{~mm}, l_{c}=115 \mathrm{~mm}$, $b=20 \mathrm{~mm}, b_{0}=10 \mathrm{~mm}$, with a transition radius of $60 \mathrm{~mm}$ (DIN 50125 shape $\mathrm{H}$ ). Tensile loading tests were also performed on the servohydraulic testing machine TT 28100 (TIRA Schalkau, Germany) at a clamping length of $98 \mathrm{~mm}$. The test length was $70 \mathrm{~mm}$ at a crosshead speed of $2.35 \mathrm{~mm} / \mathrm{min}$.

Flexural strength (DIN EN 993-6, DIN EN 843-1) and Young's modulus by static flexure (DIN EN 843-2, Method A) were determined on a servohydraulic universal testing device type TT 28100 (TIRA Schalkau, Germany) with a support distance of $125 \mathrm{~mm}$ and a crosshead speed of $0.15 \mathrm{~N} / \mathrm{mm}$ for the pressure slip casted ceramic matrix composites as well as for the zirconia preforms obtained by extrusion.

\subsubsection{Microstructural Characterization}

Microstructural characterization was conducted by digital microscopy VHX-2000 (Keyence, Germany) and scanning electron microscopy XL30 ESEM (Philips, Germany) equipped with energy dispersive X-ray spectroscopy technology (EDS). Phase identification was done using electron back scatter diffraction (EBSD) analysis (Philips XL30 with EBSD system TSL from Edax/Ametek). For EBSD analysis the samples were polished up to $1 \mu \mathrm{m}$ grain. Final polishing for $20 \mathrm{~h}$ was realized using a VibroMet2 with a $\mathrm{SiO}_{2}$-suspension MasterMet2 $(0.02 \mu \mathrm{m}$ grain size $)$ (Buehler, USA). To avoid electric charging all samples were sputtered with Pt using 
a sputter coater (Edwards, England). The crystallographic data used for phase determination were taken from ICDD-database. Detailed information are given in Berek et al. [14], Oppelt et al. [4, 5], Wenzel et al. [10, 15, 16] and Hasterok et al. [9]. Important features of the developed composites have been studied with the aid of a microfocus X-ray computed tomograph CT-ALPHA (Procon X-ray Sarstedt, Germany) equipped with a $160 \mathrm{kV}$ X-ray source and a Hamamatsu detector with $2040 \times$ 2040 pixels. For the open cell foam structure based on magnesia partially stabilized zirconia the homogeneity of the applied spray coatings was studied [9]. In case of the pressure slip casted ceramic matrix composites the homogenous distribution of the steel particles and the coarse alumina grains in the ceramic matrix was evaluated [8]. The deformation behavior of the open cell foam structures based on TRIP-steel and Mg-PSZ was evaluated using of X-ray tomography [3]. With the aid of a Zeiss Xradia 510 Versa X-ray microscope (XRM) the functionally graded beads were investigated with special regard to the formation of transition zones and the formation of cracks between the different layers [6].

\subsection{Results and Discussion}

\subsubsection{Development of TRIP-Matrix Composites via Powder Metallurgy}

\subsubsection{Open Cell Foam Structures Based on TRIP-Steel/Mg-PSZ}

TRIP-matrix composite foams have been prepared using the replica technique. In addition to the conventional coating procedure a dense coating (jacket) has been applied onto the side surfaces of the polyurethane foam template and the mass gain of the foams was registered (see Table 1.6). The linear shrinkage and the bulk density of the sintered foam structures are summarized in Table 1.7. The addition of zirconia particles in the steel matrix led to higher shrinkages. The MMCs without and with dense coating are displayed in Fig. 1.2a, b. The thickness of the dense coating has been determined to be $1.5 \mathrm{~mm}$. SEM micrographs of the typical surface regions of the samples are shown in Fig. 1.3. During thermal treatment, the TRIP-steel matrix formed a nearly dense structure with only a few pores.

Table 1.6 Mass gain of the TRIP-matrix composite foams (mean values of 3 samples, with a standard deviation of less than 5\%)

\begin{tabular}{l|l|l|l|l|l}
\hline & & $0 Z$ & $10 Z$ & $0 Z$ J & $10 Z J$ \\
\hline Mass after impregnation & $\mathrm{g}$ & 35.7 & 36.2 & 60.8 & 62.7 \\
\hline Mass after spraying & $\mathrm{g}$ & 44.2 & 46.0 & 68.6 & 71.8 \\
\hline Mass after sintering & $\mathrm{g}$ & 41.3 & 43.2 & 64.9 & 68.1 \\
\hline
\end{tabular}


Table 1.7 Bulk density and linear shrinkage of the TRIP-matrix composite foams (mean values of 3 samples, with a standard deviation of less than $3 \%$ )

\begin{tabular}{l|l|l|r|r|c}
\hline & & $0 \mathrm{Z}$ & $10 \mathrm{Z}$ & \multicolumn{1}{c}{ 0ZJ } & $10 \mathrm{ZJ}$ \\
\hline Density & $\mathrm{g} / \mathrm{cm}^{3}$ & 1.1 & 1.2 & 1.7 & 1.8 \\
\hline Linear shrinkage in height & $\%$ & 13.8 & 14.7 & 13.3 & 15.4 \\
\hline Linear shrinkage in width & $\%$ & 10.9 & 11.2 & 9.5 & 10.6 \\
\hline
\end{tabular}

(a)

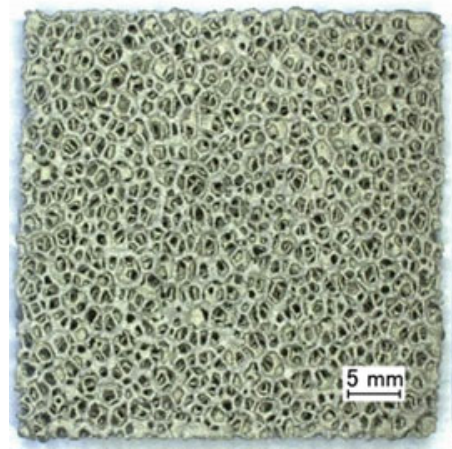

(b)

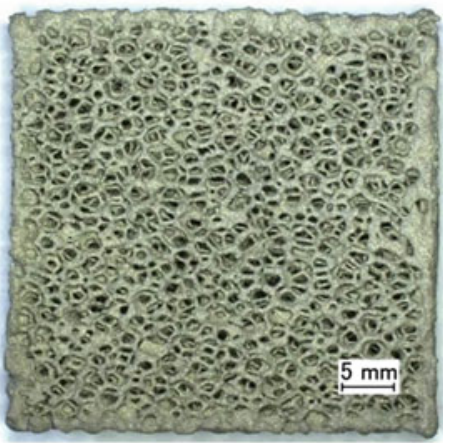

Fig. 1.2 Digital image of the TRIP-matrix composite foams a without dense coating (jacket) and b with dense coating (jacket) [3]

(a)

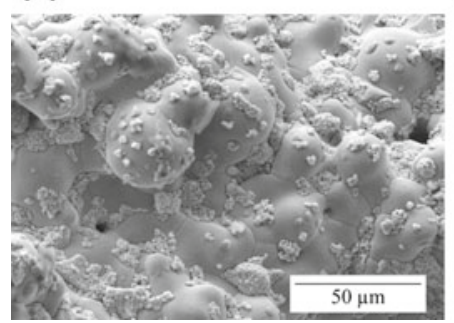

(b)

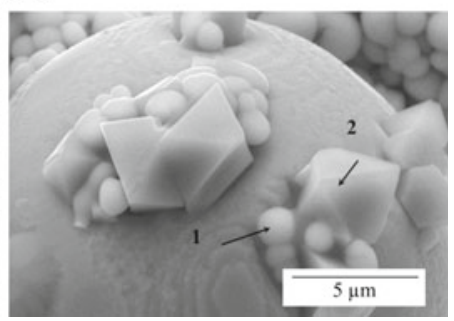

Fig. 1.3 SEM micrographs of the surface region of the composite with the composition 10ZJ [3]

With the aid of EDS measurements magnesia partially stabilized zirconia particles have been identified (see position 1 in Fig. 1.3b). The formation of spinel-type structures (see position 2 in Fig. 1.3b) has also been registered. These spinel-type structures have been analyzed by EDS. The results are summarized in Table 1.8.

Due to the significant differences in particle size between steel $\left(d_{50}=30 \mu \mathrm{m}\right)$ and zirconia $\left(d_{50}=3.0 \mu \mathrm{m}\right)$ clusters of zirconia particles were found between the steel particles. Berek et al. [17] investigated the phase composition of these reinforcing magnesia partially stabilized zirconia particles and found that approx. $80 \%$ of the 
zirconia particles transform into the monoclinic state during thermal treatment up to $1350{ }^{\circ} \mathrm{C}$ in argon atmosphere. At the grain boundaries of the zirconia particles precipitates containing $\mathrm{Mg}$ are found.

The influence of compressive stress on the structure of TRIP-matrix composite foams was investigated by in situ CT, see Fig. 1.4. A compressive strain of $45 \%$ led to apparently broken cells. During deformation the cubic and tetragonal $\mathrm{ZrO}_{2}$ (that is remaining after thermal treatment) is transformed into the monoclinic phase within the first $5 \%$ of compressive strain.

Figure 1.5 displays the compressive stress-strain curves of the developed TRIPmatrix composite foams; the corresponding values of the mass- and volume-specific energy absorption calculated according to (1.1) and (1.2) as a function of the compressive strain are presented in Table 1.9. It has to be mentioned that the calculated stress is the force divided by the nominal cross section after sintering (technical stress). The stress-strain curves of the TRIP-matrix composite foam structures with a dense coating (jacket) $0 \mathrm{ZJ}$ and $10 \mathrm{ZJ}$ show a large regime of strain hardening, followed by a plateau-like behavior with a flow stress of above $45 \mathrm{MPa}$ at approximately $15 \%$ strain, followed by a long plateau stress in which deformation occurs at almost constant stress. The successive collapse of cell walls and struts of the cellular structure accounts for this long plateau which is typical for metallic foams. The reference material 0ZJ shows lower yield strength in comparison to the reinforced composite 10ZJ. In case of the samples without any dense coating similar behavior is registered, but with significantly lower yield strengths.

Table 1.8 Chemical composition (EDS) of spot 2 in Fig. 1.3b (oxides in wt.\%, spinel-type structure)

\begin{tabular}{l|l|l|l|l|l|l|l|l|l}
\hline $\mathrm{MgO}$ & $\mathrm{Al}_{2} \mathrm{O}_{3}$ & $\mathrm{ZrO}_{2}$ & $\mathrm{~V}_{2} \mathrm{O}_{5}$ & $\mathrm{Cr}_{2} \mathrm{O}_{3}$ & $\mathrm{MnO}$ & $\mathrm{Fe}_{2} \mathrm{O}_{3}$ & $\mathrm{NiO}$ & $\mathrm{TiO}_{2}$ & $\mathrm{SiO}_{2}$ \\
\hline 2.78 & 26.45 & 5.43 & 1.33 & 34.20 & 25.51 & 2.59 & 0.47 & 0.80 & 0.42 \\
\hline
\end{tabular}

(a)

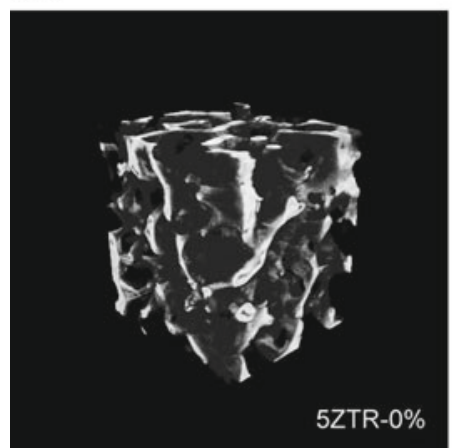

(b)

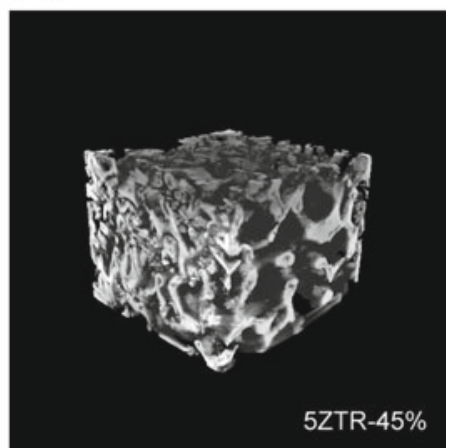

Fig. 1.4 3D CT images of a typical TRIP-matrix composite foam a before and $\mathbf{b}$ after $45 \%$ compressive strain [17] 


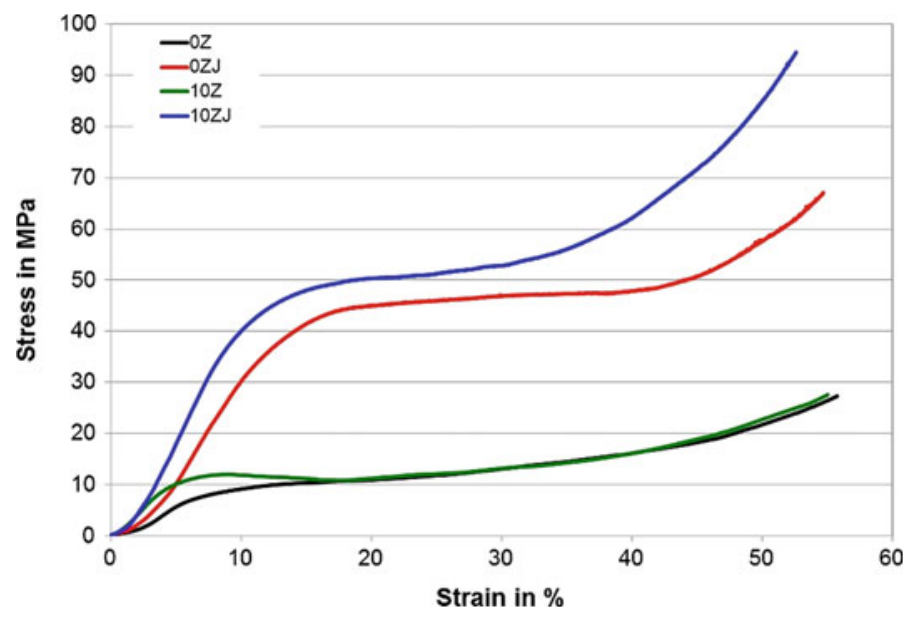

Fig. 1.5 Compressive stress-strain curves of the TRIP-matrix composite foams and the reference materials [3]

Table 1.9 Specific energy absorption (SEA) at 1, 2, 10, 20 and 50\% compressive strain

\begin{tabular}{l|l|l|l|l|l|l|l|l|r|r}
\hline & \multicolumn{2}{|l}{$1 \%$ strain } & \multicolumn{2}{l|}{$2 \%$ strain } & \multicolumn{2}{l|}{$10 \%$ strain } & \multicolumn{2}{l|}{$20 \%$ strain } & \multicolumn{2}{c}{$50 \%$ strain } \\
\cline { 2 - 12 } & $\mathrm{kJ} / \mathrm{kg}$ & $\mathrm{MJ} / \mathrm{m}^{3}$ & $\mathrm{~kJ} / \mathrm{kg}$ & $\mathrm{MJ} / \mathrm{m}^{3}$ & $\mathrm{~kJ} / \mathrm{kg}$ & $\mathrm{MJ} / \mathrm{m}^{3}$ & $\mathrm{~kJ} / \mathrm{kg}$ & $\mathrm{MJ} / \mathrm{m}^{3}$ & $\mathrm{~kJ} / \mathrm{kg}$ & $\mathrm{MJ} / \mathrm{m}^{3}$ \\
\hline $0 \mathrm{Z}$ & 0.003 & 0.004 & 0.010 & 0.012 & 0.44 & 0.50 & 1.35 & 1.53 & 5.32 & 6.01 \\
\hline $10 \mathrm{Z}$ & 0.006 & 0.007 & 0.028 & 0.034 & 0.68 & 0.84 & 1.60 & 1.96 & 5.32 & 6.52 \\
\hline $0 \mathrm{ZJ}$ & 0.003 & 0.005 & 0.010 & 0.018 & 0.68 & 1.21 & 2.92 & 5.23 & 10.99 & 19.70 \\
\hline $10 \mathrm{ZJ}$ & 0.004 & 0.007 & 0.017 & 0.031 & 0.99 & 1.87 & 3.49 & 6.57 & 13.07 & 24.61 \\
\hline
\end{tabular}

Strain hardening of the TRIP-matrix composite foams starts at smaller strains compared to the non-reinforced reference material and is independent if there is a dense side coating or not. This is of great importance and in accordance with the EBSD analysis. Thus, the reinforcement effect of magnesia partially stabilized zirconia in TRIP-matrix composites seems to be proven. This has also been observed for the mass and volume specific energy absorption, respectively. The specific energy absorption is higher in the composite foams as compared to the pure steel reference material especially up to a strain of $10 \%$ for all structures. The $10 \mathrm{ZJ}$ composite foam keeps its better performance in comparison to the reference material up to $50 \%$ compressive strain. The plotted results are average values of 5 samples with a deviation of approximately $5 \%$. 


\subsubsection{Full or Hollow TRIP-Matrix Composite Beads and Functionally Graded Beads Using Gel-Casting}

For the development of full and hollow beads an established additive system containing Darvan C and KM 2000 [8, 16] has been investigated in combination with sodium alginate. The sodium alginate was used for initial experiments since it is widely applied in food industry. Furthermore, sodium alginate has been successfully utilized for the fabrication of ceramic beads based on alumina [18]. Comprehensive rheological measurements have been carried out with a rotational viscometer (Haake RheoStress 150) with a given shear rate of $1-500 \mathrm{~s}^{-1}$ in $150 \mathrm{~s}$ with subsequent dwell of $100 \mathrm{~s}$ at maximum shear rate. The initial slurry had a powder to water ratio of $70: 30$. The addition of $0.3,0.4,0.7$ and $1.0 \mathrm{wt} . \%$ sodium alginate based on the solid content was tested. Different powder to water ratios of 80:20 and 55:45 were tested at a fixed sodium alginate content of $0.4 \mathrm{wt} . \%$. The different viscosity curves are displayed in Fig. 1.6a, b. All investigated slurries show a shear thinning behavior. For the slurries containing 0.3 and $0.4 \mathrm{wt} . \%$ sodium alginate a significant increase in viscosity can be recognized at shear rates below $50 \mathrm{~s}^{-1}$. Slurries with 0.7 and $1.0 \mathrm{wt} \%$ sodium alginate are not applicable in gel casting. Sodium alginate is a polysaccharide incorporating water in its structure; therefore highly viscous slurries are obtained that are not droppable through a cannula. Similar results are obtained if the water content is reduced to $20 \mathrm{wt} . \%$. Taking the results of the rheological measurements into consideration, the optimum amount of sodium alginate is $0.4 \mathrm{wt} . \%$ for full beads and $0.7 \mathrm{wt} . \%$ for hollow beads. In addition to the rheological characterization of the slurries experiments relating to the possible size of the composite beads have been carried out. In this context, different syringe cannulas have been tested and beads with diameters ranging from 1.6 to $2.7 \mathrm{~mm}$ were fabricated. It has been verified that completely spherical composites are obtained with a cannula having a diameter of $1.1 \mathrm{~mm}$. Subsequently, all further experiments were conducted with this cannula diameter. The sphericity of the composites does not only depend on the diameter of the cannula, but also on the distance between the injector and the

(a)

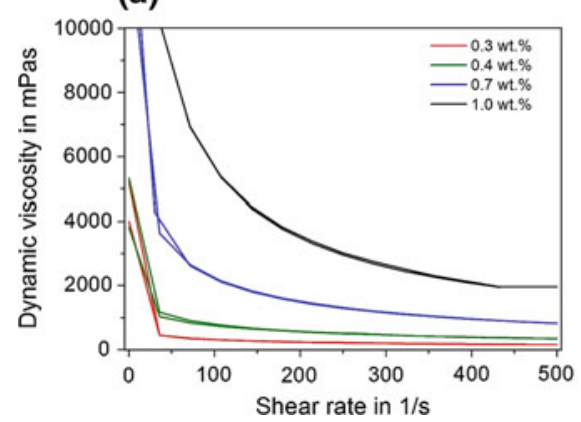

(b)

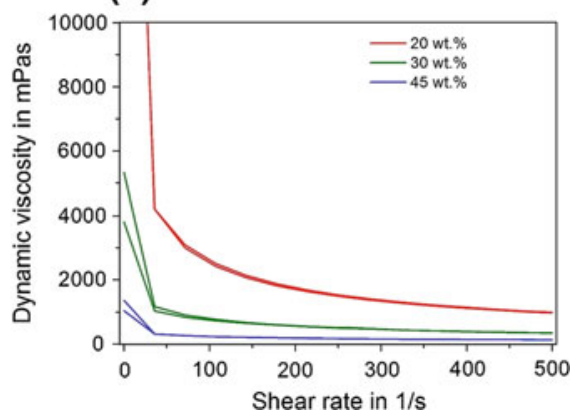

Fig. 1.6 Viscosity curves of the gel-casting slurries a with varying sodium alginate content at a powder to water ratio of 70:30; $\mathbf{b}$ with varying water content at a sodium alginate content of $0.4 \mathrm{wt} . \%$ 
hardener solution. For the fabrication of spherical samples, the distance should be $13 \mathrm{~mm}$ (at a cannula diameter of $1.1 \mathrm{~mm}$ ). At a greater distance the beads flattened and at a smaller distance "raindrop shaped" composites were produced as shown in Fig. 1.7. Hence, the level of the hardener solution should be continuously controlled during experiment. Depending on the chemical composition of the hardener solution hollow $\left(\mathrm{Ca}(\mathrm{OH})_{2}\right)$ or full beads $\left(\mathrm{CaCl}_{2}\right)$ can be produced as illustrated in Fig. 1.8 [5].

The wet green beads have been removed from the hardener solution after casting and subsequently dried. The full beads have been conventionally dried for $12 \mathrm{~h}$ at $40{ }^{\circ} \mathrm{C}$. The development of a drying procedure for the hollow beads was more challenging. The shells of the hollow beads collapse due to their weight if conventional or vacuum drying procedures are used. The differences are illustrated in Fig. 1.9a, b.

Therefore, the hollow beads had to be freeze-dried. For the freeze-drying procedure the hollow beads were placed in a freeze-dryer. The hollow beads were frozen to $-89{ }^{\circ} \mathrm{C}$ and the surrounding pressure reduced to under $6.11 \mathrm{mbar}$. According to the vapour pressure curve for ice and water, the frozen water sublimates directly from the solid to the gaseous phase without reaching the liquid state. With this drying method, the cavity within the hollow beads can be retained during the drying process and moisture is completely removed after $12 \mathrm{~h}$.

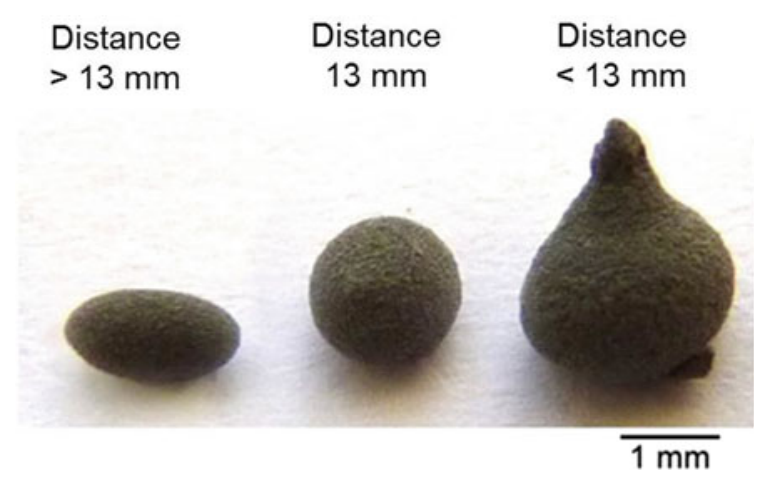

Fig. 1.7 Shape of composite beads as function of the distance between injector to hardener solution [4]

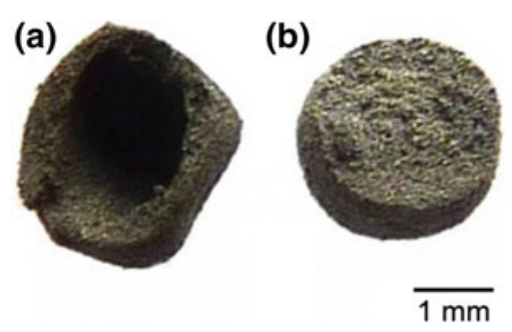

Fig. 1.8 Hollow (a) and full (b) composite beads [5] 
The debinding of the green full and hollow beads is an essential processing step in the development of TRIP-matrix composite beads. Within the present work sodium alginate (gelation agent) as well as Darvan C and KM 2000 (binder system) were used as temporary additives. The thermal removal of the organic additives is not only a critical step in terms of defect-free debinding, but also in terms of the residual carbon content affecting the chemical and phase composition of the TRIP-steel powders [19]. The decomposition behavior of the sodium alginate in synthetic air at a heating rate of $10 \mathrm{~K} / \mathrm{min}$ is displayed in Fig. 1.10a. Three exothermic peaks can be recognized at 250 , 360 and $650{ }^{\circ} \mathrm{C}$ with the corresponding total mass loss of $41 \%, 45 \%$ and $59 \%$, respectively. At $800^{\circ} \mathrm{C}$ the decomposition is completed. For the evaluation of the debinding parameters the knowledge of the oxidation tendency of the $\boldsymbol{P M}$ X8CrMnNi16-7-3 and $\boldsymbol{P M X} 3 \mathrm{CrMnNi}$ 16-7-6 steel powders is essential. The results of the thermogravimetric measurements are shown in Fig. 1.10b. The increase in mass has been registered for both types of steel powder. The $\boldsymbol{P M X} 3 \mathrm{CrMnNi16-7-6}$ steel powder possesses a lower oxidation resistance in comparison to the $\boldsymbol{P} \boldsymbol{M X} 8 \mathrm{CrMnNi16}$-7-3 steel powder.

(a)

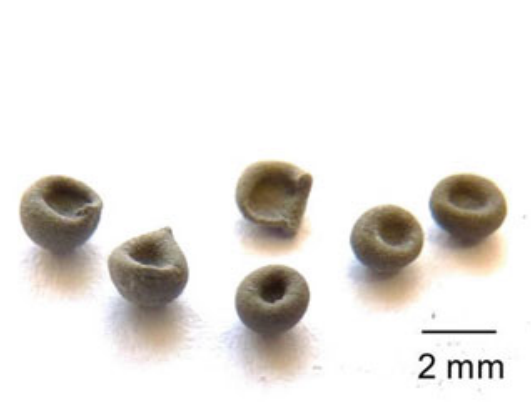

(b)

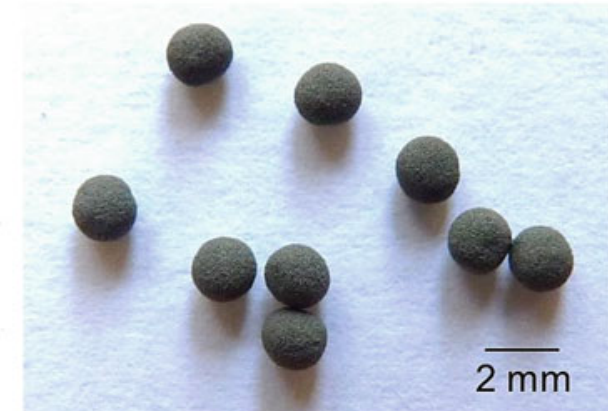

Fig. 1.9 Green hollow beads a conventionally dried b freeze-dried [7]

(a)

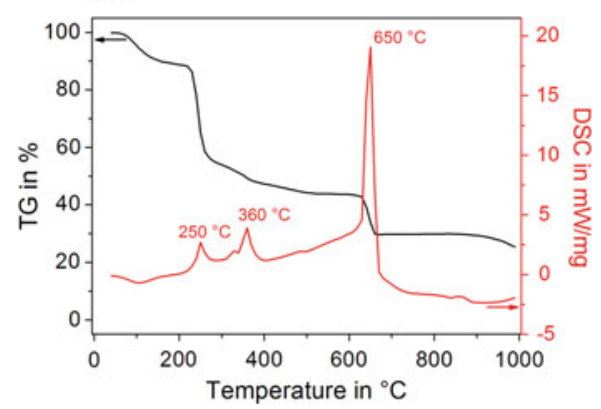

(b)

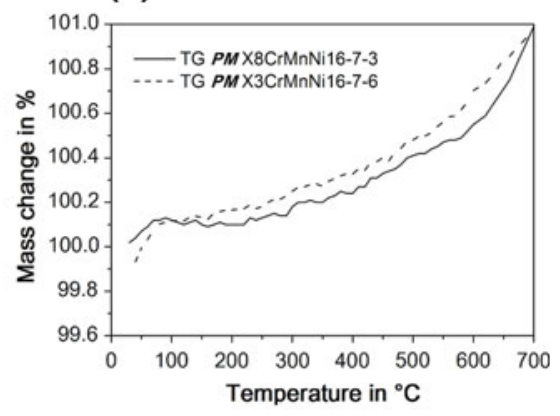

Fig. 1.10 Thermal analysis of a sodium alginate and $\mathbf{b}$ applied steel powders at a heating rate of $10 \mathrm{~K} / \mathrm{min}$ in synthetic air $[4,8]$ 
The oxidation rate significantly increases at temperatures above $400{ }^{\circ} \mathrm{C}$. Within the present work the debinding temperature was set to $660{ }^{\circ} \mathrm{C}$, which is a reasonable compromise between the binder removal and the oxidation of the steel powder. Based on the DSC/TG-analyses, the debinding experiments were conducted at $660{ }^{\circ} \mathrm{C}$ with varying dwell time at $250{ }^{\circ} \mathrm{C}$ and $660{ }^{\circ} \mathrm{C}$, respectively. The heating rate was set to $1 \mathrm{~K} / \mathrm{min}$ for a defect-free debinding of the composite beads. The residual carbon content as well as the oxygen content were determined in order to evaluate the debinding success (see Table 1.10). Using the above discussed debinding conditions, the carbon content can be reduced from $0.33 \mathrm{wt} . \%$ in the green beads to $0.048 \%$ in the binder-free beads. Within the present work the TRIP-matrix composite beads were sintered at $1350{ }^{\circ} \mathrm{C}$ as suggested by Weigelt [19]. The dwell time at maximum temperature was set to $120 \mathrm{~min}$. The sintering was conducted with excess pressure of $5 \times 10^{-4} \mathrm{MPa}$ in order to reduce the evaporation of alloying elements. Argon 5.0 was chosen as flushing gas.

Figure 1.11a represents a SEM micrograph of a full bead containing 20 vol.\% zirconia (20Z). These beads were characterized by a rough surface. The zirconia particles were evenly distributed within the steel matrix. Nevertheless poor densification of the composite during sintering led to a high porosity. A microstructural overview of the hollow beads is given in Fig. 1.11b. According to Oppelt and Aneziris [5] hollow beads are obtained if the hardener solution is highly alkaline.

Table 1.10 Results of the debinding experiments as a function of the thermal treatment (mean values of 3 measurements)

\begin{tabular}{l|c|l|l}
\hline \multicolumn{2}{l|}{ Dwell time in $\min$ at } & \multirow{2}{*}{ Carbon content in wt.\% } & \multirow{2}{*}{ Oxygen content in wt.\% } \\
\cline { 1 - 2 } $250{ }^{\circ} \mathrm{C}$ & $660{ }^{\circ} \mathrm{C}$ & & $11.50 \pm 3.61$ \\
\hline 15 & 0 & $0.049 \pm 0.004$ & $7.13 \pm 3.17$ \\
\hline 15 & 15 & $0.048 \pm 0.002$ & $6.80 \pm 1.91$ \\
\hline 15 & 30 & $0.048 \pm 0.003$ & $7.37 \pm 1.55$ \\
\hline 30 & 0 & $0.053 \pm 0.005$ & $4.23 \pm 1.06$ \\
\hline 30 & 15 & $0.053 \pm 0.003$ & $7.17 \pm 1.80$ \\
\hline
\end{tabular}

(a)

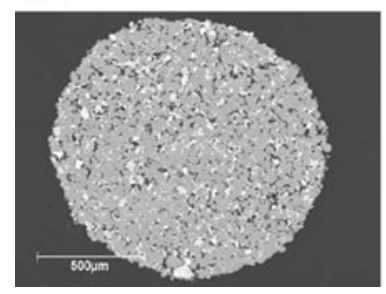

(b)

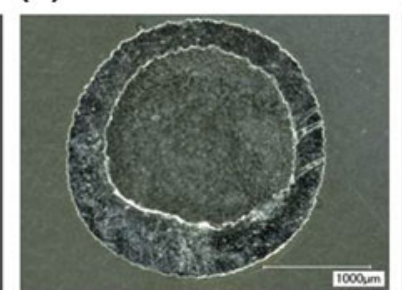

(c)

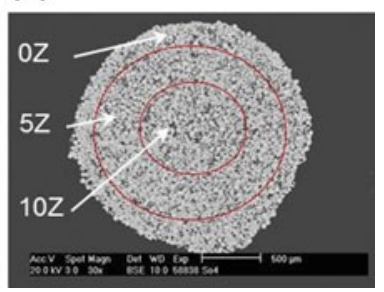

Fig. 1.11 Polished section micrographs of a single bead (SEM-micrograph) and b hollow bead (LOM-micrograph) and $\mathbf{c}$ functionally graded bead (SEM-micrograph) 
In alkaline solutions the sodium alginate is readily soluble and forms an incoherent sodium alginate sol. If this sol gets in contact with bivalent $\mathrm{Ca}$-ions the water insoluble calcium alginate gel is formed due to the ion exchange of $\mathrm{Na}^{+}$and $\mathrm{Ca}^{2+}$. During fabrication the alginate containing slurries are added dropwise into the hardener solution. Upon contact with the calcium hydroxide containing hardener solution the drop surface solidifies and a solid shell is formed. This shell inhibits the further incorporation of $\mathrm{Ca}^{2+}$-ions into the alginate structure. The transition from sodium alginate sol to calcium alginate gel proceeds exclusively within the shell and a cavity is formed. As a result of the fabrication process these cavities are irregularly shaped. Within the present study $94 \%$ of the examined hollow beads show pronounced cavities. Figure $1.11 \mathrm{c}$ shows an example for the prepared functionally graded beads. A full bead with the composition $10 \mathrm{Z}$ was coated with a slurry of the composition $5 \mathrm{Z}$ and finally a layer of the composition $0 Z$ was applied. The initial bead had a diameter of $1.8 \mathrm{~mm}$. The layer thicknesses were determined to be $76 \pm 21 \mu \mathrm{m}$ (1st layer) and $63 \pm 5 \mu \mathrm{m}$ (2nd layer). The microstructural differences are visible at higher magnifications (see Fig. 1.12). Since the sintering conditions are equal for all types of beads it can be assumed that the $\mathrm{pH}$ value of the hardener solution as well as the type of hardener agent influences the solidification process during casting. At neutral or low alkaline $\mathrm{pH}$ (using $\mathrm{CaCl}_{2}, \mathrm{pH}=7.2$ ) the ion exchange from $\mathrm{Na}^{+}$to $\mathrm{Ca}^{2+}$ takes place at lower rates. Therefore the transition from sodium alginate sol to calcium alginate gel is decelerated and the resulting beads have a higher porosity in comparison to the hollow beads. In case of the hollow beads a better densification of the material is recognized. As stated above at higher alkaline $\mathrm{pH}$ (using $\mathrm{Ca}(\mathrm{OH})_{2}, \mathrm{pH}=13.4$ ) the ion exchange as well as the transition from sol to gel takes place at higher rates. For the development of the functionally graded beads a different approach was chosen. The different layers were sprayed onto a full bead. The composition of the spraying slurries was adopted from the spray coating procedure for the development of TRIPmatrix composite foams. In Fig. 1.12c a functionally graded bead is shown. The 2nd coating had the composition $\mathrm{OZ}$ and is characterized by a high residual porosity.

For all types of TRIP-matrix composite beads precipitation can be found at the steel/steel grain boundaries. The chemical and phase composition of these precipitations have been analyzed using EDS/EBSD. The results are displayed in Fig. 1.13. The lattice parameters of the considered phases for EBSD-analysis are given by

(a)

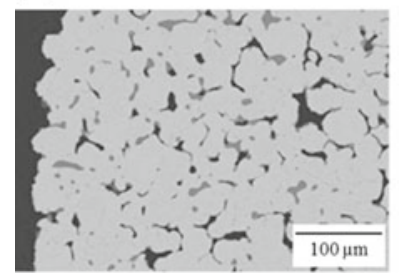

(b)

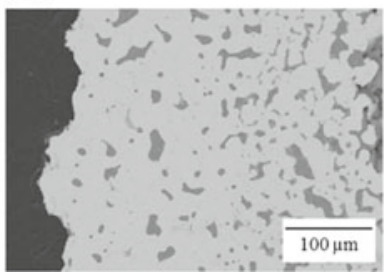

(c)

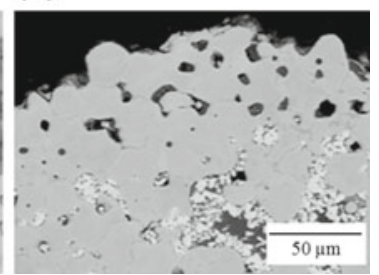

Fig. 1.12 SEM micrographs of a single bead, $0 Z$ and $\mathbf{b}$ hollow bead, $0 Z$ and $\mathbf{c}$ functionally graded bead, 10Z-5Z-0Z at higher magnifications [6] 

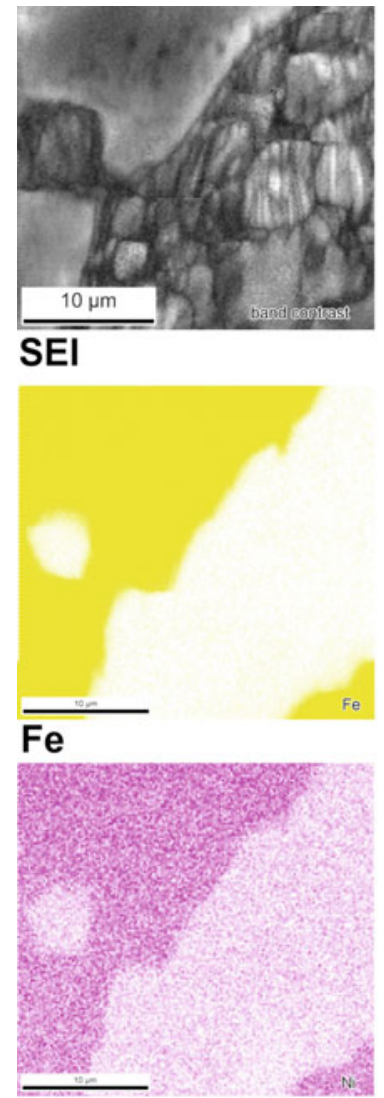

$\mathrm{Ni}$

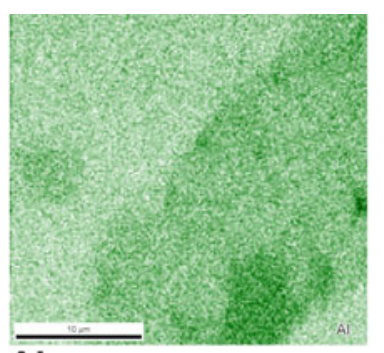

Al

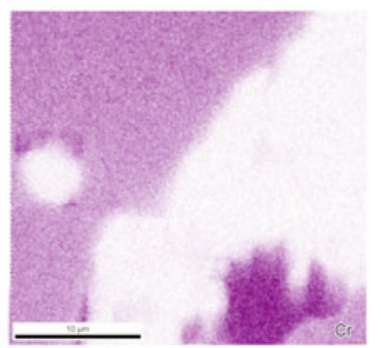

$\mathrm{Cr}$

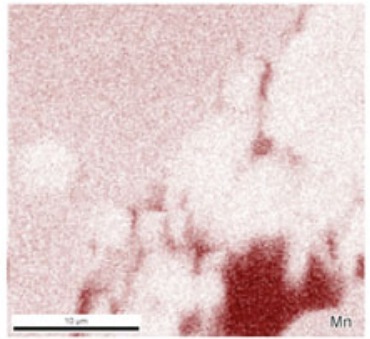

Mn
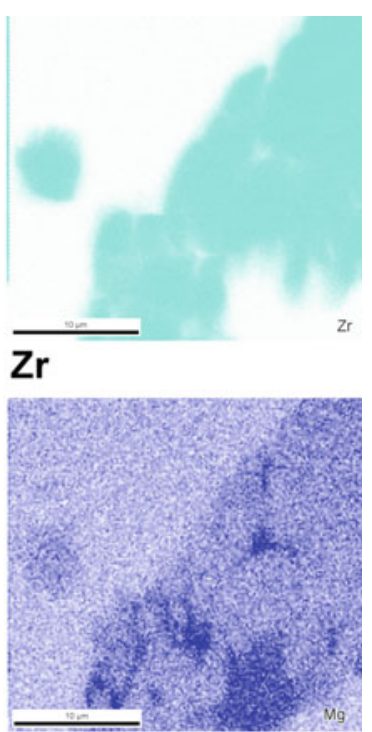

Mg

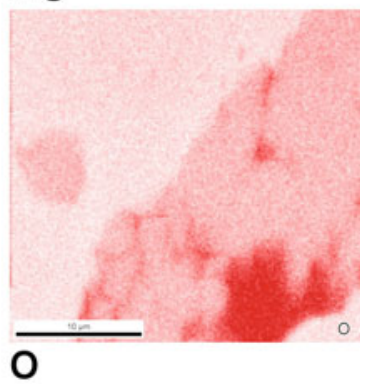

Fig. 1.13 EDS mapping of a full TRIP-matrix composite bead, composition 20Z (polished surface) [4]

Oppelt [7]. The steel matrix can be clearly distinguished due to the presence of $\mathrm{Fe}$ and $\mathrm{Ni}$. The zirconia particles can be recognized due to the $\mathrm{Zr}$-distribution pattern. Mixed spinel formation during sintering occurred due to diffusion processes [10] and is indicated by the distribution of $\mathrm{Al}, \mathrm{Mg}, \mathrm{O}, \mathrm{Mn}$ and $\mathrm{Mg}, \mathrm{Cr}$. At the grain boundaries steel/steel three different types of precipitates $\mathrm{Mn}-\mathrm{Cr}-\mathrm{O}, \mathrm{Mn}-\mathrm{Si}-\mathrm{O}$ and $\mathrm{Cr}-\mathrm{C}$ have been found. By means of EBSD the precipitations could be identified as $\mathrm{MnCr}_{2} \mathrm{O}_{4}$, $\mathrm{Mn}_{2} \mathrm{SiO}_{4}$ and $\mathrm{Cr}_{7} \mathrm{C}_{3}$. The formation of carbides has been reduced due to optimization of the thermal processes.

The physical properties of the different TRIP-matrix composite beads are summarized in Table 1.11. For the full beads it can be recognized that the shrinkage increases if zirconia particles are incorporated in the steel matrix. Due to the chosen hardener agent $\left(\mathrm{CaCl}_{2}\right)$ the transition from sodium alginate sol to calcium alginate gel during casting is decelerated. The fabricated full beads therefore have high 
Table 1.11 Properties of the TRIP-matrix composite beads, after sintering at $1350{ }^{\circ} \mathrm{C}$

\begin{tabular}{l|l|l|l|l|l|l}
\hline & $\begin{array}{l}\text { Shrinkage } \\
\%\end{array}$ & $\begin{array}{l}\text { Bulk } \\
\text { density } \\
\mathrm{g} / \mathrm{cm}^{3}\end{array}$ & $\begin{array}{l}\text { Open } \\
\text { porosity } \\
\%\end{array}$ & $\begin{array}{l}\text { Compressive } \\
\text { strength } \\
\mathrm{MPa}\end{array}$ & $\begin{array}{l}\text { Strain at } \\
\text { failure \% }\end{array}$ & $\begin{array}{l}\text { Total } \\
\text { specific } \\
\text { energy } \\
\text { absorption } \\
\mathrm{kJ} / \mathrm{kg}\end{array}$ \\
\hline
\end{tabular}

\begin{tabular}{l|c|l|r|r|r|c}
\hline \multicolumn{7}{l}{ Full beads } \\
\hline $0 Z$ & $5.7 \pm 0.1$ & 4.1 & 11.3 & $398.3 \pm 17.3$ & $29.4 \pm 0.8$ & $11.5 \pm 0.4$ \\
\hline $5 Z$ & $16.7 \pm 0.0$ & - & 5.9 & $344.4 \pm 18.1$ & $13.5 \pm 0.7$ & $6.3 \pm 0.4$ \\
\hline $10 Z$ & $22.0 \pm 0.1$ & 4.7 & 3.7 & $359.1 \pm 15.1$ & $16.6 \pm 0.2$ & $7.9 \pm 0.4$ \\
\hline $20 Z$ & $16.1 \pm 0.1$ & 6.1 & 15.0 & $240.3 \pm 13.5$ & $16.5 \pm 0.2$ & $3.9 \pm 0.1$ \\
\hline Hollow beads & $38.7 \pm 5.9$ & 5.6 & 10.2 & $61.4 \pm 3.2$ & $15.6 \pm 3.1$ & $2.4 \pm 0.4$ \\
\hline $0 Z$ & $26.1 \pm 2.6$ & 4.9 & 9.0 & $98.8 \pm 12.7$ & $15.3 \pm 2.2$ & $3.7 \pm 0.2$ \\
\hline $5 Z$ & $24.5 \pm 5.4$ & 4.8 & 12.7 & $104.0 \pm 30.3$ & $10.4 \pm 4.5$ & $1.5 \pm 0.5$ \\
\hline $10 Z$ &
\end{tabular}

Functionally graded beads (10Z-95Z-0Z)

\begin{tabular}{l|l|l|l|c|c|c}
\hline dipped & $24.4 \pm 4.8$ & 6.8 & 23.0 & $49.6 \pm 4.9$ & $4.6 \pm 0.8$ & $0.4 \pm 0.1$ \\
\hline sprayed & $27.0 \pm 1.8$ & 7.7 & 10.1 & $551.3 \pm 59.3$ & $21.5 \pm 3.0$ & $13.7 \pm 3.5$ \\
\hline
\end{tabular}

porosities in the green stage (35-47\%). After sintering the composition $10 \mathrm{Z}$ has the lowest open porosity of $3.7 \%$ and the highest shrinkage of $22.0 \%$. For the hollow beads shrinkages ranging from $24.5 \%$ (10Z) to $38.7 \%(0 \mathrm{Z})$ have been determined. It has to be noted that the cavities of the hollow beads are reduced during thermal treatment. Therefore a higher overall shrinkage was measured. The hollow beads containing 5 and $10 \mathrm{vol} \%$ zirconia show higher open porosities in comparison to the full beads. The functionally graded beads (FGS) were prepared by dip or spray coating of composites beads with the initial composition 10Z. Hence, the shrinkages of the FGS correspond to the shrinkage of the full beads with the composition 10Z. The difference in open porosity can be attributed to the choice of coating procedure. With the aid of spray coating a fine spray is generated and it presumably closed the open pores of the initial bead. This effect has not been recognized for the dip coated material. The mechanical properties of the different TRIP-matrix composite beads are also summarized in Table 1.11. The functionally graded beads (spray coating) exhibit the highest compressive strength with $551 \mathrm{MPa}$. The compressive strength of the reference material (full bead) with the composition $0 \mathrm{Z}$ was determined to be $399 \mathrm{MPa}$. This material also shows the highest strain at failure with 30\%, whereas the functionally graded beads (spray coating) have a strain at failure of $21.5 \%$. The functionally graded beads also show the highest total specific energy absorption with $13.7 \mathrm{~kJ} / \mathrm{kg}$, followed by the reference material with $11.5 \mathrm{~kJ} / \mathrm{kg}$. In Table 1.12 the specific energy absorption of the different TRIP-matrix composite beads is displayed as a function of compression strain. The full beads with the composition $0 \mathrm{Z}$ and the functionally graded beads (spray coated) allow a compression of up to $20 \%$. At this compression the FGSs show the highest specific energy absorption with $10.7 \mathrm{~kJ} / \mathrm{kg}$. 
At a compression of up to $15 \%$ all zirconia reinforced beads have a higher specific energy absorption compared to the reference material 0Z. Oppelt [7] has found that the reinforcing zirconia particles in the TRIP-matrix show a stress-assisted phase transformation. In Fig. 1.14, the results of the compressive testing are given for all developed TRIP-matrix composite beads. The full beads have a 4 times higher strength in comparison to the hollow beads. Up to a compression of $15 \%$ the full beads of the composition $5 \mathrm{Z}$ and $10 \mathrm{Z}$ show a significant higher strength than the reference material $0 Z$. The highest strength has been determined for the functionally graded beads even at compression above $15 \%$.

\subsubsection{TRIP-Matrix Composites via Paper-Manufacturing Technology}

Square paper sheets with $200 \mathrm{~mm}$ in length have been formed on a laboratory sheetforming device. Figure 1.15 shows the microstructure of as-fabricated and calendered green sheets. In contrast to the processing of pre-ceramic paper, where both filler particles and pulp fibers develop a negative surface charge in water, the steel particles used as fillers remained non-charged in water. Coagulation and flocculation therefore only took place for pulp fibers in the suspension due to the addition of organic additives. Figure 1.15a illustrates the domination of that fiber-to-fiber bonds. During wet paper processing via filtration, the steel particles were incorporated in between the fiber network, and steel clusters could be found. The solids retention was greater than $90 \mathrm{wt} . \%$. The as-fabricated paper had a high porosity and surface roughness (Fig. 1.15c), which could be significantly reduced by calendering at $30 \mathrm{kN} / \mathrm{mm}$ (Fig. 1.15b, d). During calendering the steel particles deformed plastically due to the high surface load and may have undergone a martensitic phase transformation, which was reversible upon heat treatment.

Table 1.12 Specific energy absorption $\left(\mathrm{SEA}_{\mathrm{m}}\right)$ in $\mathrm{kJ} / \mathrm{kg}$ at $5,10,15$ and $20 \%$ strain

\begin{tabular}{l|l|l|l|l}
\hline & $5 \%$ strain & $10 \%$ strain & $15 \%$ strain & $20 \%$ strain \\
\hline Full beads & $0.19 \pm 0.02$ & $1.11 \pm 0.06$ & $2.73 \pm 0.18$ & $5.22 \pm 0.22$ \\
\hline $0 Z$ & $0.74 \pm 0.01$ & $3.34 \pm 0.13$ & - & - \\
\hline $5 Z$ & $0.75 \pm 0.01$ & $3.39 \pm 0.22$ & $7.27 \pm 0.18$ & - \\
\hline $10 Z$ & $0.29 \pm 0.01$ & $1.27 \pm 0.03$ & $3.08 \pm 0.3$ & - \\
\hline $20 Z$ & $0.26 \pm 0.05$ & $1.14 \pm 0.06$ & $2.08 \pm 0.40$ & - \\
\hline Hollow beads & $0.39 \pm 0.02$ & $1.45 \pm 0.14$ & $3.14 \pm 0.30$ & - \\
\hline $0 Z$ & $0.57 \pm 0.05$ & $1.51 \pm 0.53$ & - & - \\
\hline $5 Z$ & $0.34 \pm 0.04$ & - & - & - \\
\hline $10 Z$ & $0.64 \pm 0.19$ & $2.95 \pm 0.54$ & $6.89 \pm 0.90$ & $10.7 \pm 0.23$ \\
\hline Functionally graded beads $(10 Z-95 Z-0 Z)$ &
\end{tabular}




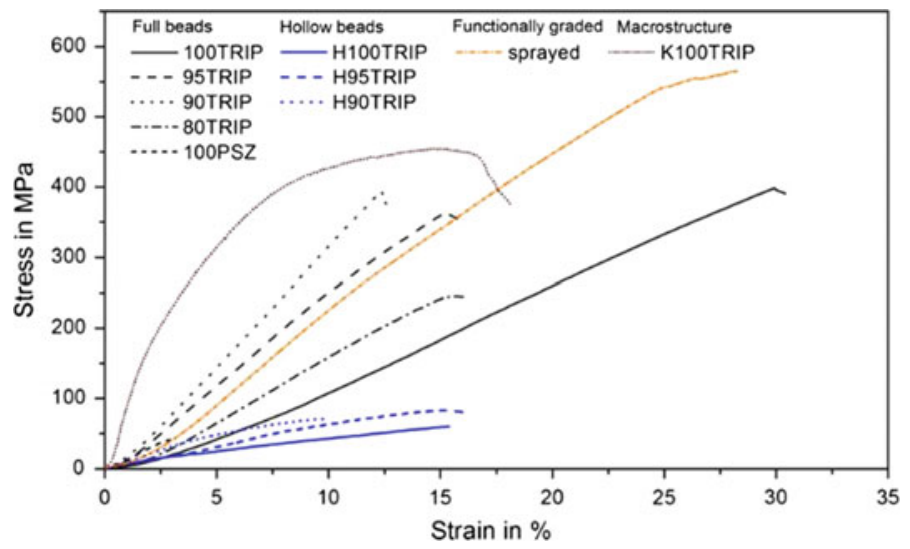

Fig. 1.14 Stress-strain curves for the different TRIP-matrix composite beads [7]

(a)

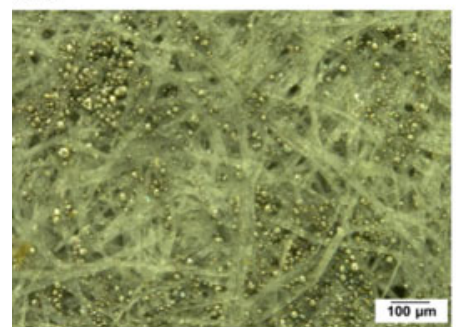

(c)

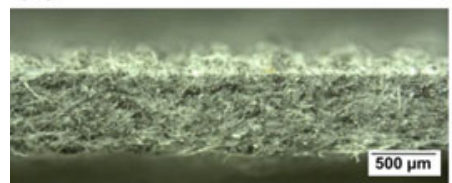

(b)

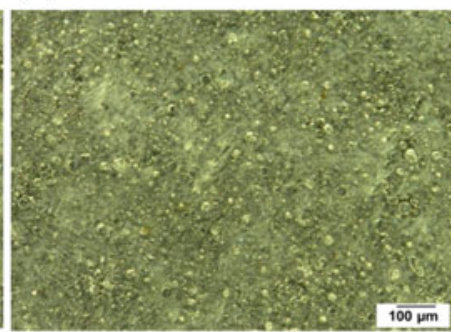

(d)

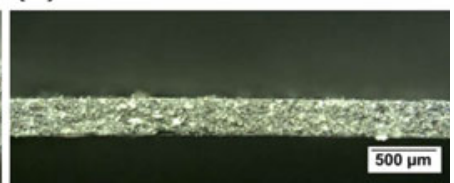

Fig. 1.15 LOM micrographs of a green paper sheet, composition 0Z, PMX8CrMnNi16-7-3. Top surface view: a uncalendered, b calendered at $30 \mathrm{kN} / \mathrm{mm}$. Cross-sectional view: $\mathbf{c}$ uncalendered, d calendered at $30 \mathrm{kN} / \mathrm{mm}[15]$

The properties of the green composites are summarized in Table 1.13. In the asfabricated state, the fibers were loosely arranged with many interspaces, whereas calendering led to the firm embedding of the fibers between the filler particles. In consequence, the total porosity and the surface roughness are decreased due to calendering, which also increases the tensile strength of the calendered samples. The calendered sheets therefore offer enough stability to be further processed (e.g. punching of samples for determination of tensile strength after sintering, preparation of corrugated cardboard structures). 
Table 1.13 Properties of the TRIP-matrix paper composites in green state

\begin{tabular}{l|l|l|l|l}
\hline Recipe & & $0 \mathrm{Z}$ & $5 \mathrm{Z}$ & $10 \mathrm{Z}$ \\
\hline Thickness as-fabricated & $\mathrm{mm}$ & $1.00 \pm 0.05$ & $0.97 \pm 0.05$ & $0.97 \pm 0.06$ \\
\hline Thickness after calendering & $\mathrm{mm}$ & $0.31 \pm 0.03$ & $0.31 \pm 0.01$ & $0.31 \pm 0.1$ \\
\hline Tensile strength as-fabricated & $\mathrm{N} / \mathrm{mm}^{2}$ & $6.1 \pm 0.9$ & $5.3 \pm 0.6$ & $5.2 \pm 0.5$ \\
\hline Tensile strength after calendering & $\mathrm{N} / \mathrm{mm}^{2}$ & $13.2 \pm 1.7$ & $14.0 \pm 2.9$ & $15.6 \pm 3.2$ \\
\hline
\end{tabular}

(a)

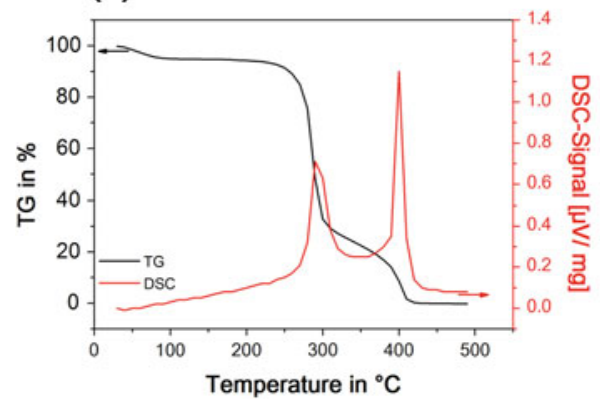

(b)

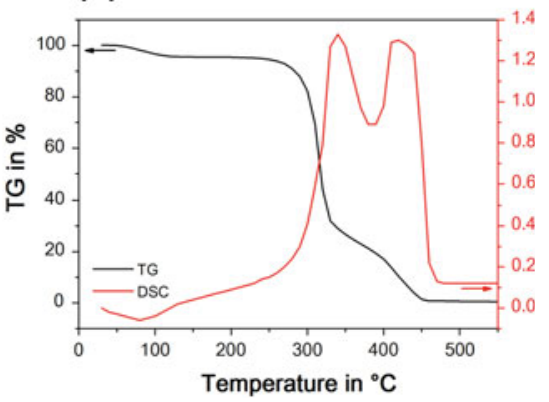

Fig. 1.16 DSC/TG analysis of the cellulose fibers in oxidizing atmosphere applying different heating rates: a $1 \mathrm{~K} / \mathrm{min}$, b $5 \mathrm{~K} / \mathrm{min}$ [15]

The debinding of the calendered paper sheets is an essential processing step in the development of TRIP-matrix composites by paper-manufacturing technology. The total organic quantity of the as-fabricated paper sheets was $40-45$ vol.\%. The thermal removal of the organic additives is therefore not only a critical step in terms of defect-free debinding, but also in terms of residual carbon (resulting from an insufficient debinding) affecting the chemical and the phase composition of the TRIPsteel matrix. The thermal decomposition behavior of the cellulose pulp fibers at heating rates of 1 and $5 \mathrm{~K} / \mathrm{min}$ are summarized in Fig. 1.16. For both heating rates, two exothermic peaks can be distinguished. At a heating rate of $5 \mathrm{~K} / \mathrm{min}$, the peaks are shifted to higher temperatures and appear less pronounced. At a heating rate of $1 \mathrm{~K} / \mathrm{min}$, the maxima of both exothermic reactions are given at 290 and $400{ }^{\circ} \mathrm{C}$. The decomposition was completed at $420^{\circ} \mathrm{C}$. At a heating rate of $5 \mathrm{~K} / \mathrm{min}$, the exothermic reactions shifted to 340 and $430{ }^{\circ} \mathrm{C}$, respectively, and the reaction was completed at $460{ }^{\circ} \mathrm{C}$.

As a result of the DSC/TG analyses the debinding rate was set to $0.5 \mathrm{~K} / \mathrm{min}$. The maximum debinding temperature was set to $460{ }^{\circ} \mathrm{C}$, with a dwell time of $90 \mathrm{~min}$. The carbon content for the composition $0 \mathrm{Z}$ after debinding was determined to be $0.044 \%$, which corresponds to the carbon content of the initial steel powder. The microstructure of the sintered sample 5Z is displayed in Fig. 1.17. The paper manufacturing technology requires the use of cellulose pulp fibers, which are thermally removed by a debinding process, leaving pores within the material. The sintering at 
$1350{ }^{\circ} \mathrm{C}$ with a dwell time of $60 \mathrm{~min}$ did not result in a sufficient densification of the steel matrix. The incorporated zirconia particles form agglomerates, which are embedded in the interstices of the steel particles and the process derived pores. It can be furthermore recognized that no interfacial reaction occurred between the zirconia particles and the surrounding steel matrix. Nevertheless, precipitates are formed at the grain boundaries steel/steel.

The chemical as well as the phase composition of the precipitates has been analyzed using EDS/EBSD. According to the EDS mappings two different types of precipitates have formed during sintering as shown in Fig. 1.18a, b. In the center of the investigated sample the precipitates are composed of chromium, manganese, and carbon and were identified as trigonal $(\mathrm{Cr}, \mathrm{Mn}, \mathrm{Fe})_{7} \mathrm{C}_{3}$. The second type of precipitation was occasionally found at the sample edges. These precipitates are composed of manganese, silicon, and oxygen and have been identified as orthorhombic $\mathrm{Mn}_{2} \mathrm{SiO}_{4}$. The manganese silicate is surrounded by an iron, chromium, carbon rich area that was identified as trigonal $(\mathrm{Cr}, \mathrm{Mn}, \mathrm{Fe})_{7} \mathrm{C}_{3}$. The potential of the paper-derived TRIPmatrix composites regarding the desired deformation-assisted austenite to martensite phase transformation is significantly lowered due to the presence of carbides. The influence of the sintering atmosphere on the formation of carbides is discussed in [8]. In a further investigation the calendered paper sheets have been sintered in a purified argon atmosphere with the aim to prohibit the formation of carbide precipitations. The resulting microstructure is shown in Fig. 1.19. Obviously, the incorporated zirconia particles form agglomerates and they are embedded within the pores. The formation of carbide precipitates has not been registered. According to EDS/EBSD the steel matrix shows segregations with higher concentrations of chromium and lower concentrations of nickel than the surrounding matrix. Furthermore, the material contains randomly dispersed oxide precipitations that were most likely formed during heat treatment. These oxide precipitations have been identified as orthorhombic $(\mathrm{Mg}$, $\mathrm{Mn})_{2} \mathrm{SiO}_{4}$.

If the thermal treatment was conducted in a non-purified atmosphere, the mechanical properties of the paper-derived metal-matrix composites were deteriorated due

(a)

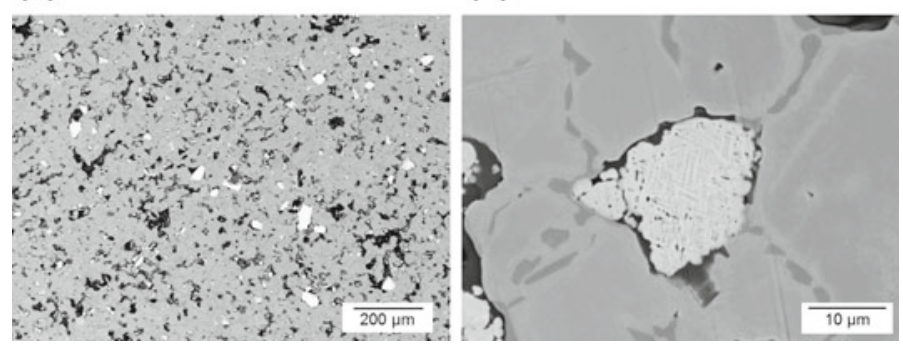

Fig. 1.17 SEM micrographs (BSE-mode) of the sintered composites prepared by papermanufacturing technology (light grey: zirconia, dark grey: steel matrix with precipitations) [8] 
(a)

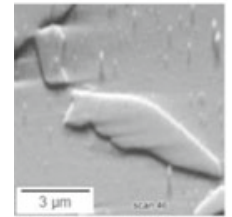

(SEM)

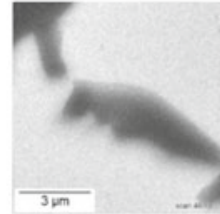

(Fe)

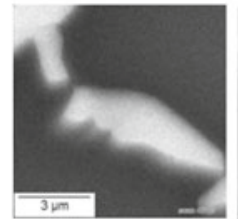

(Cr)

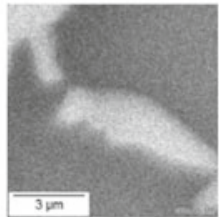

(Mn)

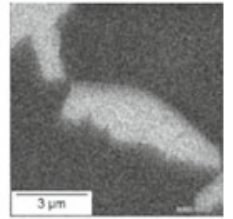

(C)

(b)

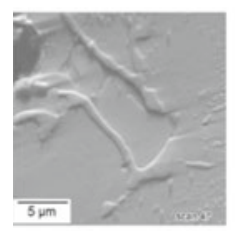

(SEM)

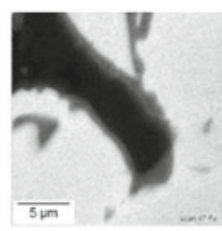

(Fe)

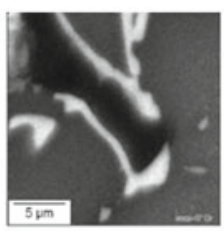

(Cr)

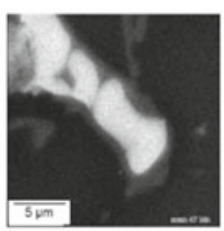

(Mn)

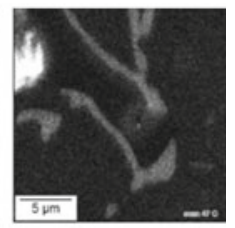

(C)

Fig. 1.18 EDS mapping of the reference material $0 \mathrm{Z}$ at the grain boundaries, sintered at $1350{ }^{\circ} \mathrm{C}$, $\mathbf{a}$ in the center of the sample, $\mathbf{b}$ at the edge of the sample [8]

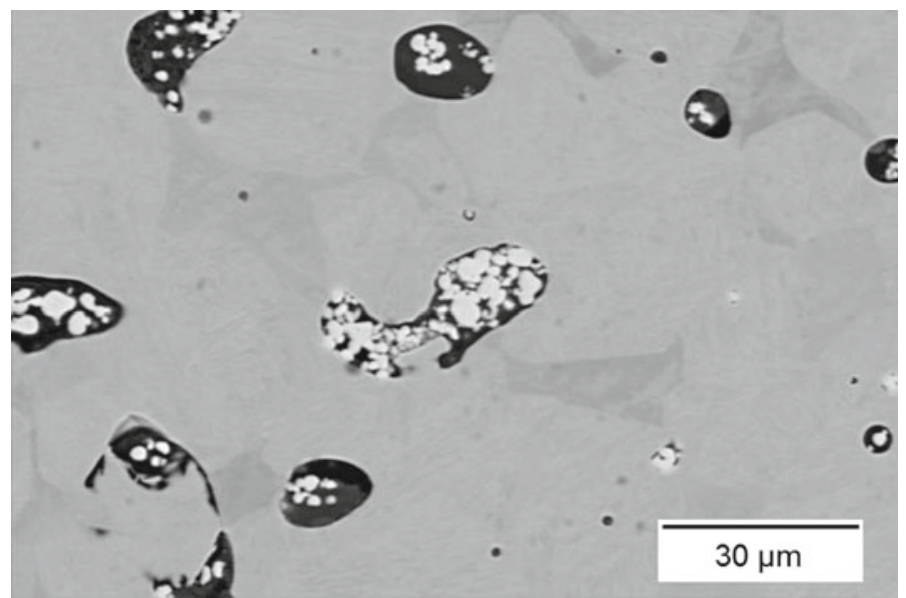

Fig. 1.19 SEM micrograph (BSE-mode) of the paper-derived TRIP-matrix composite 10Z sintered in a purified argon atmosphere [8]

to the presence of carbides. The highest tensile strength was determined for the reference material $0 \mathrm{Z}$ with $176.6 \pm 12.1 \mathrm{MPa}$ at a total porosity of $66 \%$. The composition $5 Z$ ( 5 vol.\% zirconia) showed a lower tensile strength of $123.3 \pm 3.1 \mathrm{MPa}$. For the composite 10Z (10 vol.\% zirconia) a tensile strength of $103.3 \pm 14.4 \mathrm{MPa}$ was determined. The materials failed at a maximum strain of $0.6 \%$ and showed brittle fracture behavior. 


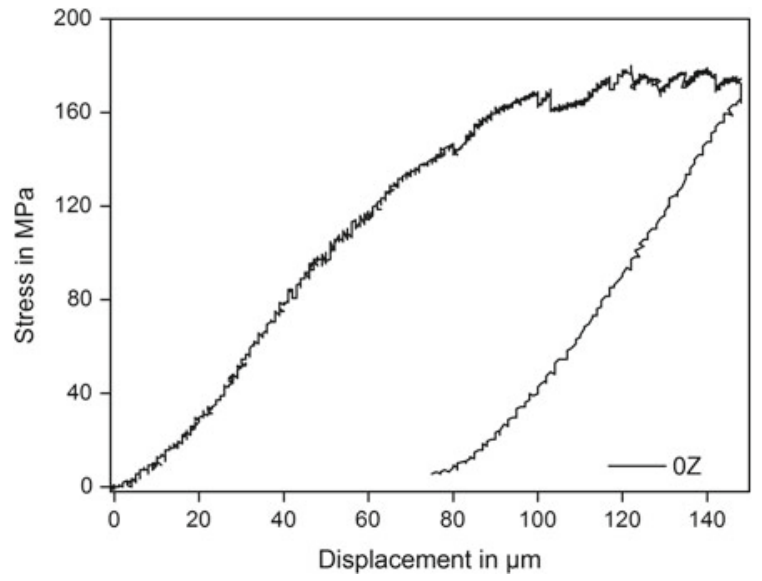

Fig. 1.20 Stress-displacement curve of the reference material $0 \mathrm{Z}$ during tensile load testing [8]

An in situ tensile test was carried out for the reference material $0 \mathrm{Z}$ in a scanning electron microscope MIRA 3 XMI (Tescan, Czech Republic) in order to characterize the deformation and damage behavior of the material under quasi-static load at a crosshead speed of $1 \mu \mathrm{m} / \mathrm{s}$. The evolution of the microstructure was registered as a function of the crosshead displacement. The corresponding stress-displacement curve is shown in Fig. 1.20.

Figure 1.21a shows the microstructure of the reference material $0 \mathrm{Z}$ in its initial state. The carbide precipitates are clearly visible at the grain boundaries. Pores are filled with $\mathrm{Mn}_{2} \mathrm{SiO}_{4}$. At a crosshead displacement of $110 \mu \mathrm{m}$ the carbide precipitates start to break, and cracks are initiated on macroscopic scale (see Fig. 1.21b, c). The single cracks joined to a large main crack when the crosshead displacement is further increased, see Fig. 1.21d. The crack tip passes along the carbide grain boundaries toward bigger pores. The precipitates debond from the steel matrix and fracture in a transgranular manner.

In case of the paper-derived TRIP-matrix composites sintered in a purified argon atmosphere significant higher tensile strength has been determined. A purified atmosphere and the optimized composition of the paper-sheets led to tensile strength of $170.6 \pm 18.7$ for the composition $0 \mathrm{Z}$ and $142.4 \pm 10.5 \mathrm{MPa}$ for the composition $10 \mathrm{Z}$ at total porosities of $26 \%$. The incorporation of commercially available zirconia fibers led to further improvements of the mechanical performance. At a fiber incorporation of $3 \mathrm{vol} . \%$ the tensile strength was determined to be $207.0 \pm 17.4 \mathrm{MPa}$ at a total porosity of $25 \%$. However, these optimized TRIP-matrix composites showed also a brittle fracture behavior. 

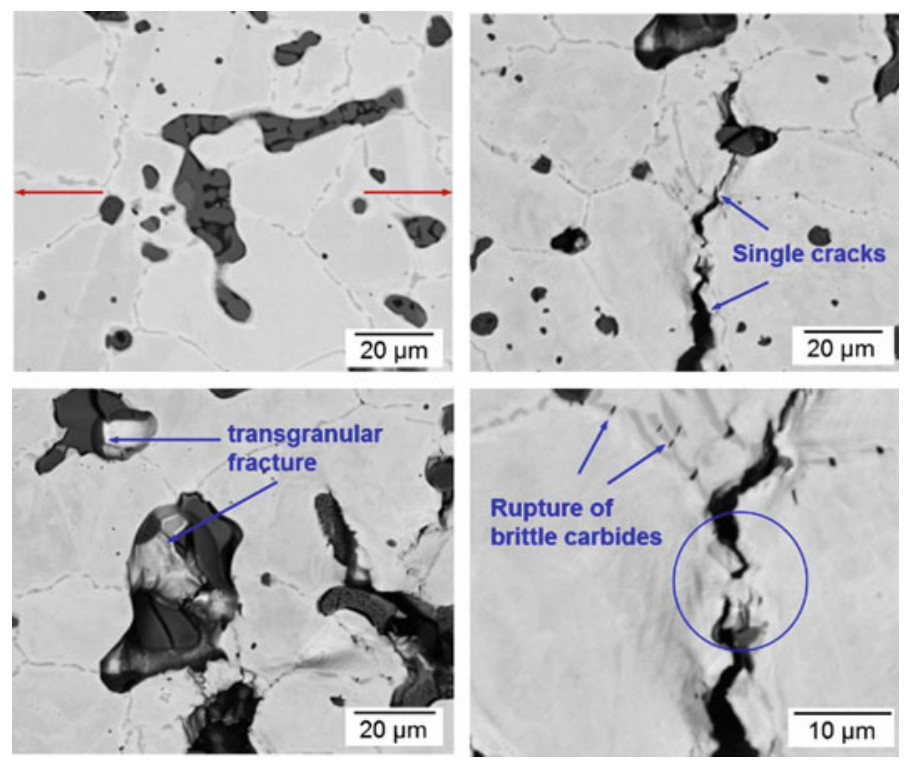

Fig. 1.21 SEM micro-graphs of the reference material $(0 Z)$ during tensile loading at different displacements (red arrows: load direction) [8]

\subsubsection{Development of TRIP-Matrix Composites via Metal Melt Infiltration of Ceramic Preforms}

\subsubsection{Open Cell Foam Structures Based on Magnesia-Partially Stabilized Zirconia}

Open cell foam structures based on magnesia partially stabilized zirconia have been prepared using the replica technique. In a preliminary study an adequate additive system has been developed. Comprehensive rheological measurements have been carried out. In Fig. 1.22 the viscosity curves for the different spraying slurries are displayed. According to literature [20] typical shear rates for spray processes are $10^{3}-10^{5} \mathrm{~s}^{-1}$. At a shear rate of $1000 \mathrm{~s}^{-1}$ the viscosities of the slurries have been determined to be $126 \mathrm{mPas}$ ( $40 \mathrm{wt} . \%$ water), $100 \mathrm{mPas}$ (45 wt. \% water) and $63 \mathrm{mPas}$ (55 wt.\% water). These low viscosities favor the formation of a fine spray during the spray coating procedure. The appropriate additive system additionally assists to keep the slurries stable in idle state. It was recognized that the conventional spray coating procedure led to a poor coating of the foam struts especially in the foam center. If the spray coating procedure was done air stream assisted, a better deposition of the spray droplets on the polyurethane foams has been established. In addition to that less pore blocking has been registered. With the aid of computer tomography the homogeneity of the coatings has been analyzed [9]. In Fig. 1.23, a comparison between conventional and airstream assisted coating procedure is given. 


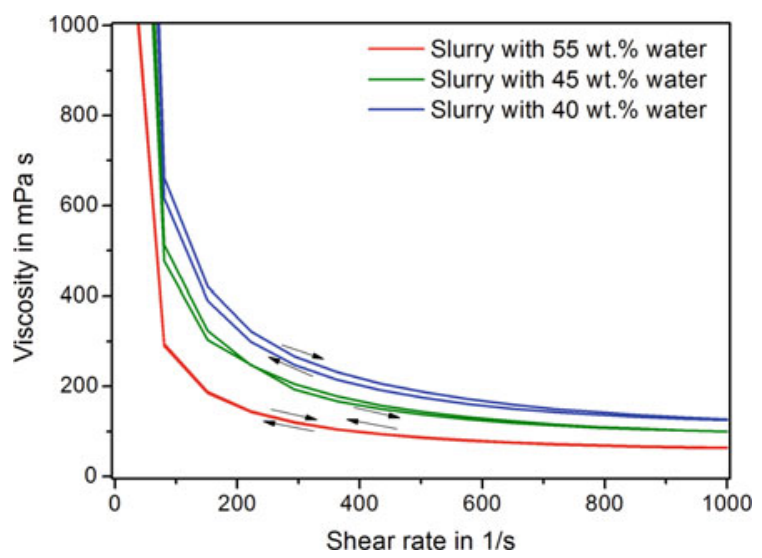

Fig. 1.22 Viscosity curves of the zirconia slurries at different powder to water ratios [9]

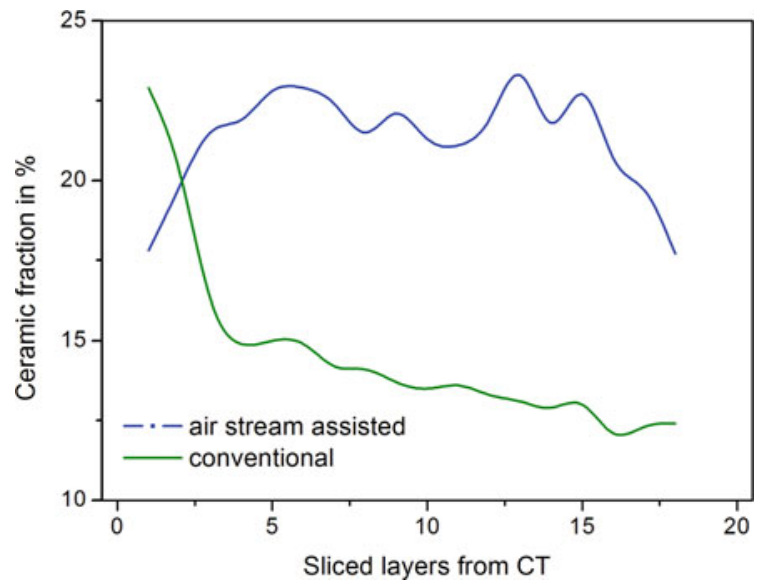

Fig. 1.23 Homogeneity of coated open foam cell structures using the different spray coating procedures [9]

For the conventional spray coating, the ceramic portions are mainly deposited on the surface of the open cell foam structures. In the first layer of the foam it was determined to be $22 \%$ and decreases to $15 \%$. In the center of the open cell foam structure the ceramic portion is negligible. Quite different results have been found if the spraying procedure was done air stream assisted. It can be seen that the ceramic fraction was always greater than $20 \%$ throughout the considered volume of the open cell foam structure.

The influence of the solid content of the spraying slurry on the homogeneity of the spray coating has also been investigated. The slurry with $55 \mathrm{wt} \%$ water had a 


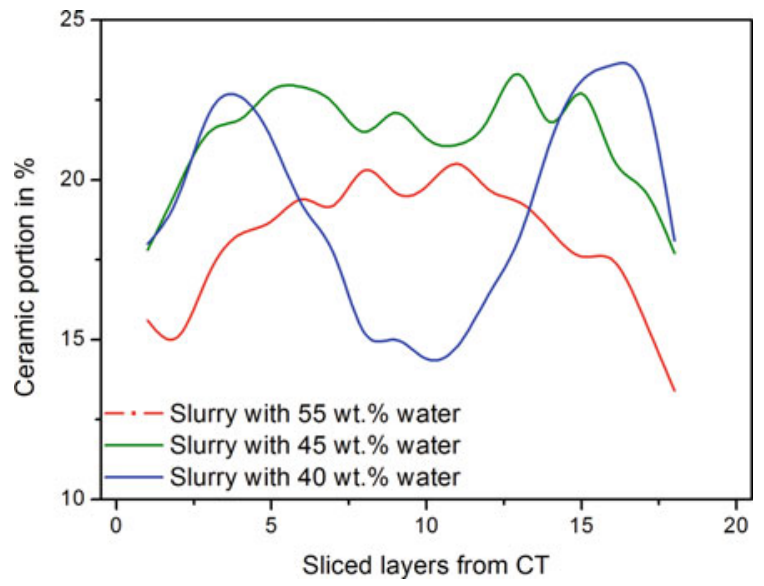

Fig. 1.24 Influence of the solid content of the spraying slurry on the homogeneity of the spray coating [9]

viscosity of $63 \mathrm{mPas}$ and a yield stress of $13 \mathrm{~Pa}$. Due to the low viscosity the slurry easily penetrates the foam structures.

As it can be seen in Fig. 1.24 the ceramic portion in the middle of the foam was determined to be greater than $20 \%$. However, the ceramic portion is rather small on the upper surface of the sprayed foam. Presumably the yield stress of the slurry is exceeded due to the air pressure of the spray. For the slurry with $40 \mathrm{wt} \%$ water a different effect can be seen. On the upper surface of the open cell foam structure the ceramic fraction was determined to be greater than $22 \%$. Due to the higher yield stress the slurry strongly adheres onto the struts of the top surface and is not transported deeper into the structure. The best distribution of the ceramic fraction throughout the entire foam structure has been achieved if the slurry with $45 \mathrm{wt}$. $\%$ water was used for the spray coating procedure. Due to the yield stress of $20 \mathrm{~Pa}$, the slurry remains on the struts. The viscosity of this slurry was determined to be $100 \mathrm{mPas}$ and is therefore able to deeply infiltrate the foam structure.

The sintered open cell foam structures were infiltrated by a Cast X5CrMnNi167-7 steel melt in order to obtain TRIP-matrix composites. The phase composition of the infiltrated foam structures has been analyzed with the aid of EBSD. In Fig. 1.25, a SEM micrograph of the polished sample surface is presented. According to the EBSD-phase analysis the infiltrated foam structure contained $4.5 \%$ monoclinic zirconia, $49.8 \%$ tetragonal zirconia and $45.7 \%$ cubic zirconia. Thus, approximately $50 \%$ of the ceramic material is able to transform stress-assisted. No martensite has been detected by EBSD-analysis; the analyzed part consisted of 100\% austenite. 


\subsubsection{Extrusion Technology for Honeycombs and Randomly Arranged Spaghetti-Filters}

Ceramic preforms of honeycomb or spaghetti filter type have been prepared via extrusion technology. After sintering at $1650{ }^{\circ} \mathrm{C}$ in oxidizing atmosphere the preforms have been infiltrated by a Cast X5CrMnNi16-7-7 steel melt in order to obtain TRIPmatrix composites. For a sufficient infiltration the preforms had to be preheated to $1000{ }^{\circ} \mathrm{C}$. The honeycombs were joined by a cold joining technique. Schärfl et al. [11] prepared spaghetti filters with a diameter of $70 \mathrm{~mm}$ and a height of $120 \mathrm{~mm}$ in one piece. Wenzel et al. [10] extruded spaghetti filter discs of with a diameter of 50 and $25 \mathrm{~mm}$ height. Before infiltration, these filters were stack to give a preform of $120 \mathrm{~mm}$ height. For the honeycomb structures as well as for the spaghetti filters an incomplete infiltration was registered. The metal melt froze during casting, presumably due to the high ceramic portion as well as due to the dense arrangement of the strands/honeycombs. A sufficient infiltration has been obtained if the hollow spaghetti filters have been used, see Fig. 1.26. It can be seen that the hollow strands are infiltrated. Presumably the thermal shock at the beginning of the steel casting caused the cracking of the hollow zirconia strands; moreover there is a significant density gradient between zirconia and steel. At the interface between zirconia and steel a crack network has been formed.
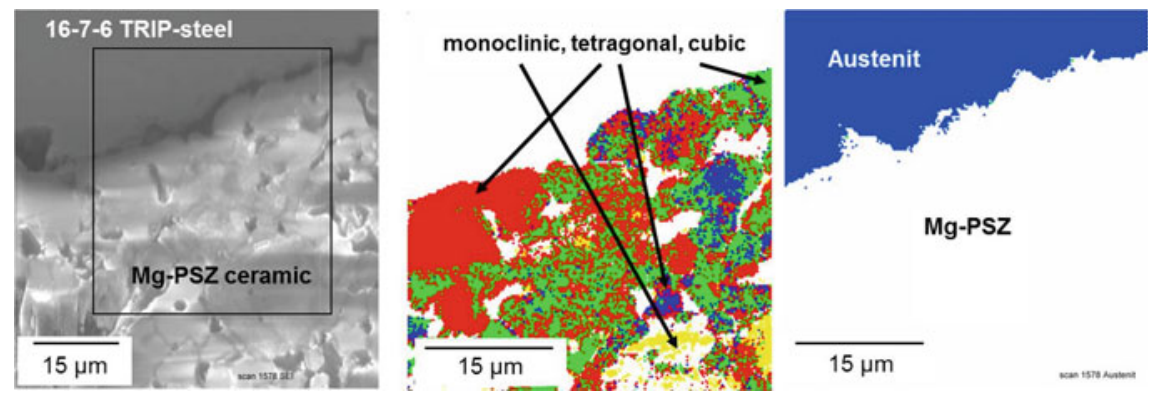

Fig. 1.25 SEM micrograph of the infiltrated open cell foam structure and the corresponding results of the EBSD-analysis [9]

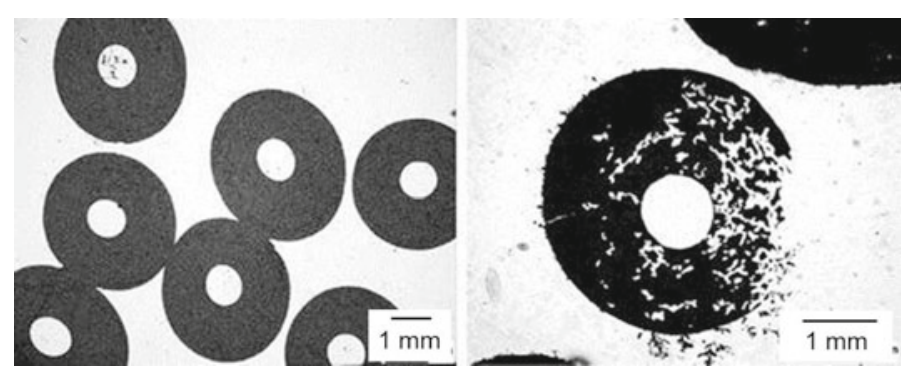

Fig. 1.26 LOM micrograph showing infiltrated hollow rods [11] 


\subsubsection{Development of Ceramic Matrix Composites via Powder Metallurgy}

Another focus of the present work was the fabrication of ceramic matrix composites using pressure slip casting. The developed materials were based on zirconia and alumina with additions of up to 20 vol.\% TRIP-steel powder (PM X8CrMnNi16-73 ). The zirconia matrix composites were cast as fine and coarse grained components, whereas the alumina matrix composites were only cast as coarse grained components. In a previous studies [16] an organic binder system containing KM 1001, KM 2000 and Optapix PAF 35 has been successfully established for the rheological stabilization of zirconia-steel slurries. For the casting of large components $\left(200 \times 200 \times 38 \mathrm{~mm}^{3}\right)$ two additional binders, Welan gum and Konjac flour, had to be applied in order to guarantee the dimensional stability of the cast green bodies after demoulding. Due to the adjustment of the solid content as well as the optimization of the particle packing the casting times for these large components could be set to $90 \mathrm{~min}$ (fine grained slurries) and to $25 \mathrm{~min}$ (coarse grained slurries). The maximum casting pressure was $2 \mathrm{MPa}$. After drying the cast components were sintered at $1550{ }^{\circ} \mathrm{C}$ in argon atmosphere. The microstructure of the $\mathrm{CMCs}$ for the components containing $80 \mathrm{vol} \%$ alumina (coarse) or 80 vol.\% zirconia (fine) is exemplarily shown in Fig. 1.27. The homogenous distribution of the steel particles within the matrix materials has been verified with the aid of the microfocus X-ray computed tomograph. As a result of the casting technology and the sintering temperatures the pressure slip casted ceramic matrix composites features open porosities of $\geq 27 \%$.

The wear behavior of the pressure slip casted composites has been investigated. Therefore the surfaces of the materials have been polished using different grinding media down to $1 \mu \mathrm{m}$ grain size. Wear tests have been performed using a pin-on-disc tribometer with a WC-Co pin at room temperature under a normal force of $50 \mathrm{~N}$ and at a sliding speed of $0.05 \mathrm{~m} / \mathrm{s}$ and a maximum sliding distance of $200 \mathrm{~m}$. The wear tracks are at least $4 \mathrm{~mm}$ in width and can be clearly distinguished from the untreated surface as shown in Fig. 1.28. The wear resistance of the test specimens is characterized by their mass loss and the wear rates of the materials as given in

(a)

(b)

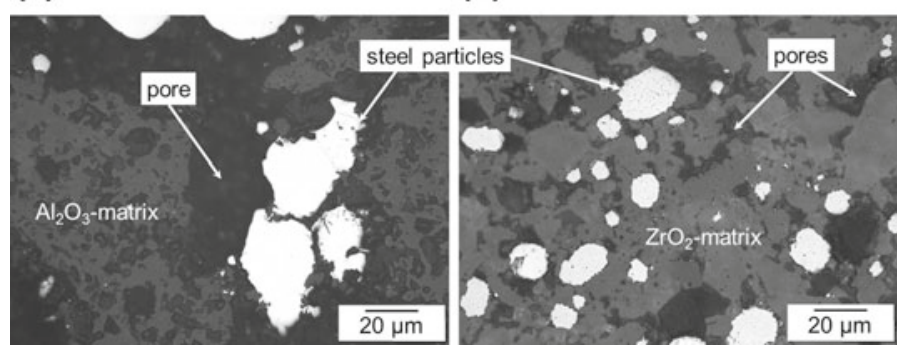

Fig. 1.27 LOM micrograph of pressure slip casted CMCs of the compositions a 80 vol.\% alumina coarse and $\mathbf{b} 80$ vol.\% zirconia fine 
Table 1.14. All investigated materials present severe wear with wear rates in the order of $10^{-1}$ to $10^{-4} \mathrm{~mm}^{3} / \mathrm{Nm}$. The wear tracks are characterized by abrasion, adhesion as well as fracture processes. Especially the coarse grained zirconia matrix composites are characterized by severe abrasive wear. The finer zirconia matrix material was significantly worn off; as a result also the coarser grains broke out of the matrix. For the coarse alumina composites identical wear mechanisms have been identified. With the aid of EDS the deposition of the counter body material tungsten carbide-cobalt in the wear track was registered. The fine grained zirconia matrix composites are

(a)

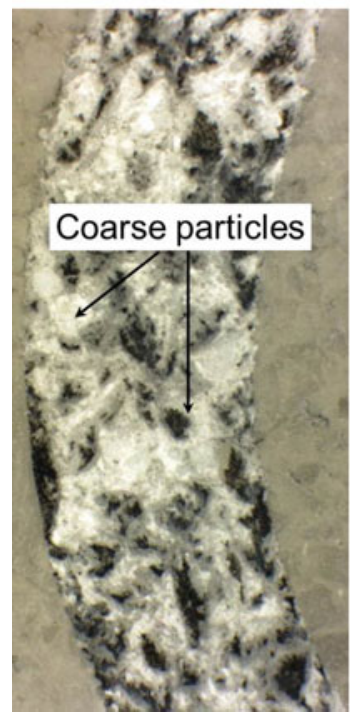

(b)

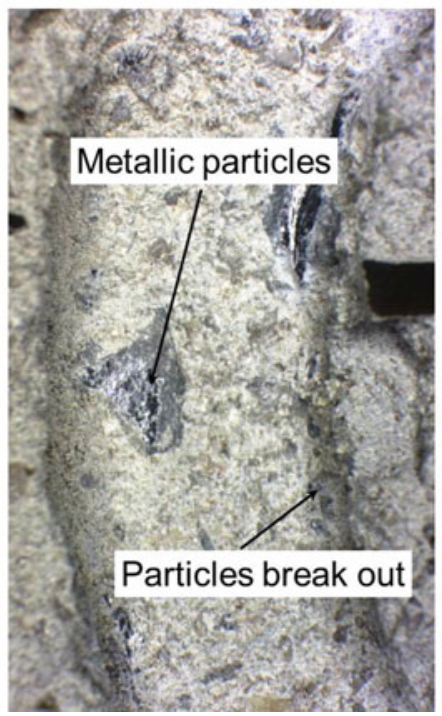

(c)

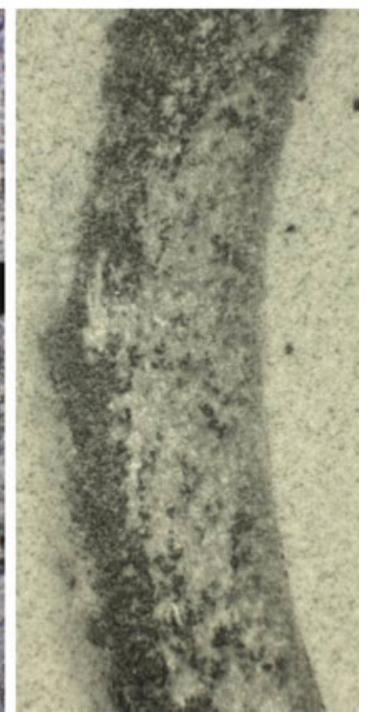

Fig. 1.28 Wear tracks of a 100 vol.\% alumina (coarse), b 90 vol.\% zirconia (coarse), c 100 vol.\% zirconia (fine)

Table 1.14 Mass loss and wear rate of the investigated ceramic matrix composites

\begin{tabular}{l|c|l|c}
\hline Matrix material & Metal fraction & Mass loss $\mathrm{g}$ & Wear rate $10^{-2} \mathrm{~mm}^{3} / \mathrm{Nm}$ \\
\hline \multirow{3}{*}{ Alumina (coarse) } & 0 & $0.015 \pm 0.009$ & $0.050 \pm 0.024$ \\
\cline { 2 - 4 } & 10 & $0.033 \pm 0.032$ & $0.103 \pm 0.117$ \\
\cline { 2 - 4 } & 20 & $0.014 \pm 0.009$ & $0.037 \pm 0.027$ \\
\hline \multirow{2}{*}{ Zirconia (coarse) } & 0 & $1.949 \pm 1.322$ & $49.099 \pm 33.318$ \\
\cline { 2 - 4 } & 10 & $1.233 \pm 0.405$ & $11.828 \pm 38.863$ \\
\cline { 2 - 4 } & 20 & $0.853 \pm 0.421$ & $7.789 \pm 3.847$ \\
\hline \multirow{3}{*}{ Zirconia (fine) } & 0 & $0.008 \pm 0.011$ & $0.024 \pm 0.025$ \\
\cline { 2 - 4 } & 10 & $0.027 \pm 0.034$ & $0.081 \pm 0.028$ \\
\cline { 2 - 4 } & 20 & $0.034 \pm 0.001$ & $0.076 \pm 0.022$ \\
\hline
\end{tabular}


characterized by less material abrasion. The continuous stresses may cause surface fatigue in such a way that occasionally larger fragments of the material break out. In these areas the material abrasion is enhanced due to the rough surfaces. The wear behavior of the pressure slip casted composites is similar to existing results in literature. It may be significantly improved if the sintering parameters will be optimized, e.g. performing of the sintering at higher temperatures $\left(1650-1700{ }^{\circ} \mathrm{C}\right)$. However, a compromise between sintering temperatures of the ceramic material and the reinforcing metal particles has to be found.

\subsubsection{Development of Ceramic Components Using Alternative Technologies}

Intensive research work has been conducted in terms of the development of partially stabilized zirconia fibers using the electrospinning technology. The fibers were prepared from polyvinylpyrrolidone (PVP), $\mathrm{ZrOCl}_{2} \cdot 8 \mathrm{H}_{2} \mathrm{O}$ and $\mathrm{Y}\left(\mathrm{NO}_{3}\right)_{3} \cdot 6 \mathrm{H}_{2} \mathrm{O}$. The appearance of the as-spun fibers with a mean fiber diameter of $225 \mathrm{~nm}$ is displayed in Fig. 1.29. The thermal decomposition behavior has been studied with the aid of DSC/TG-analysis. Three different peaks have been identified and the corresponding total weight loss was determined to be $80 \%$. The first weight loss of $15 \%$ from room temperature to $200{ }^{\circ} \mathrm{C}$ is caused by the removal of water and ethanol. The second weight loss $(47 \%)$ is related to exothermic reactions as shown by the DSC curve, see Fig. 1.30. The exothermic peaks at 358, and $400{ }^{\circ} \mathrm{C}$ are associated with the decomposition of the PVP. From 400 to $504{ }^{\circ} \mathrm{C}$ there was a weight loss of approx.

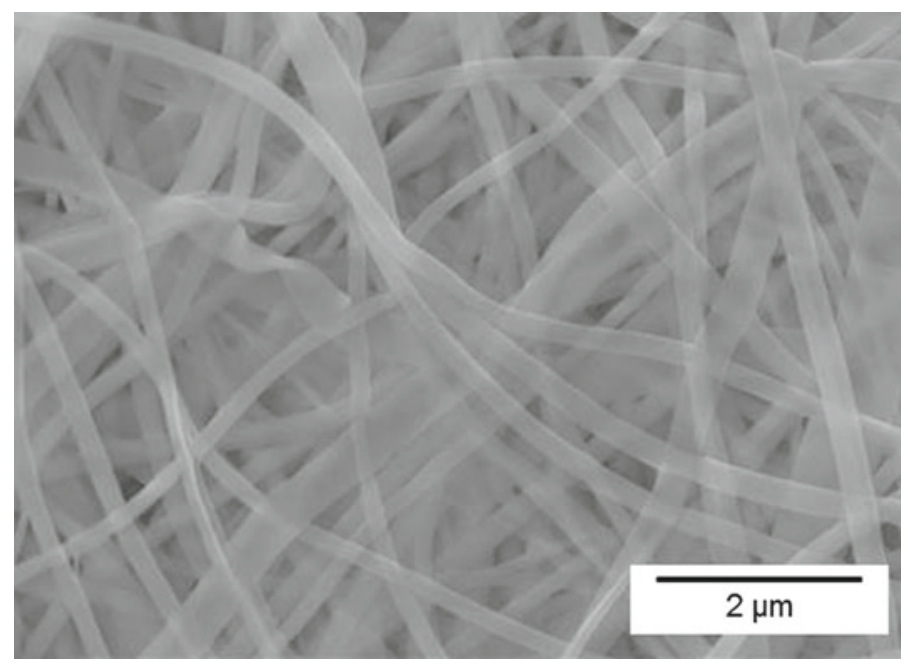

Fig. 1.29 SEM micrograph of the as-spun fibers with a mean fiber diameter of $225 \mathrm{~nm}$ 
$19 \%$, which can be assigned to the transition from $\mathrm{ZrOCl}_{2}$ to $\mathrm{ZrO}_{2}$ and the further decomposition of PVP.

The as-spun fibers have been sintered at $700,1100,1350$ and $1650{ }^{\circ} \mathrm{C}$ with heating rates of $1 \mathrm{~K} / \mathrm{min}$ and $10 \mathrm{~K} / \mathrm{min}$. The evolution of the crystalline structure has been analyzed using X-ray diffraction. If the sintering was conducted at $700{ }^{\circ} \mathrm{C}$ only tetragonal zirconia has been identified, see Fig. 1.31. With increasing sintering temperature the peaks become tapered. Sintering at $1100{ }^{\circ} \mathrm{C}$ with a heating rate of $1 \mathrm{~K} / \mathrm{min}$ led to a decrease of the tetragonal phase in intensity and a monoclinic pattern appears, see

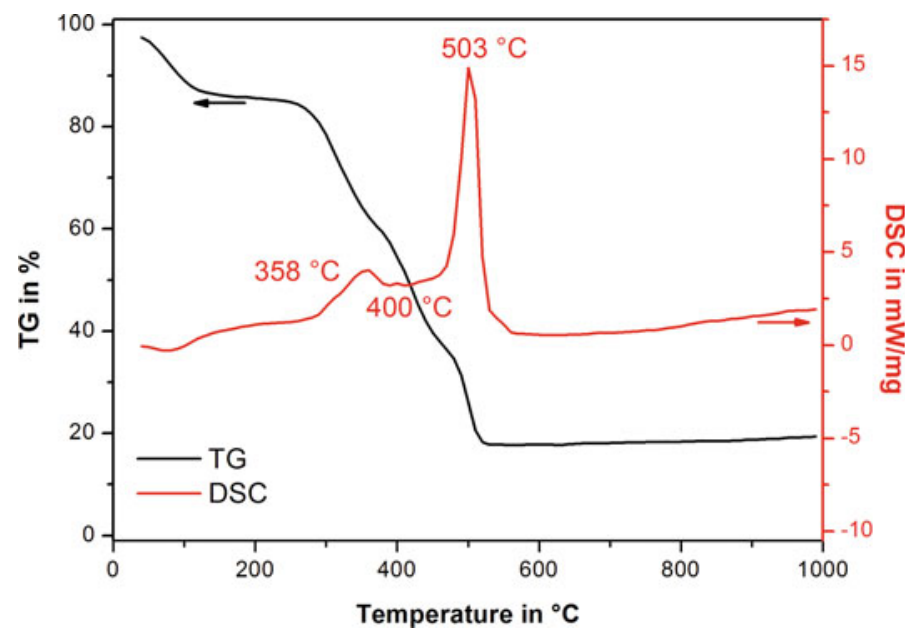

Fig. 1.30 DSC/TG-analysis of the as-spun fibers

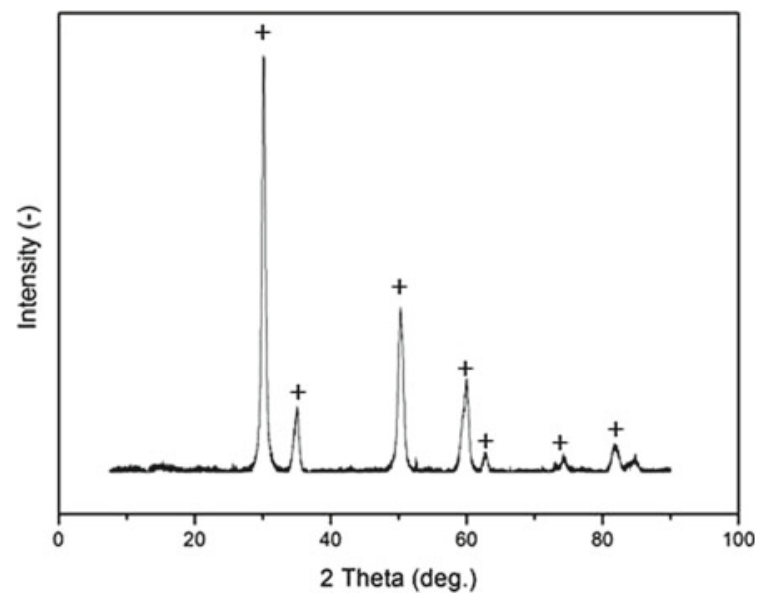

Fig. 1.31 X-ray diffraction pattern of the yttria stabilized zirconia fibers after sintering at $700{ }^{\circ} \mathrm{C}$, tetragonal phase indicated by + 
Fig. 1.32. These results are consistent with the observations made by Davies et al. [21] and may be attributed to the coarsening of the zirconia grains/fibers. If the heating rate has been increased to $10 \mathrm{~K} / \mathrm{min}$ (at the same sintering temperature) the formation of a monoclinic phase and coarsening of the zirconia fibers/grains could not be registered, see Figs. $1.32 \mathrm{~b}$ and 1.33. At sintering temperatures of 1350 and $1650{ }^{\circ} \mathrm{C}$ the tetragonal phase dominates, since the thermal treatment has been conducted in the tetragonal solid solution field. At sintering temperatures of $1350{ }^{\circ} \mathrm{C}$, the fiber structure disappears as shown in Fig. 1.34. The final microstructure is characterized by a high open porosity.

(a)

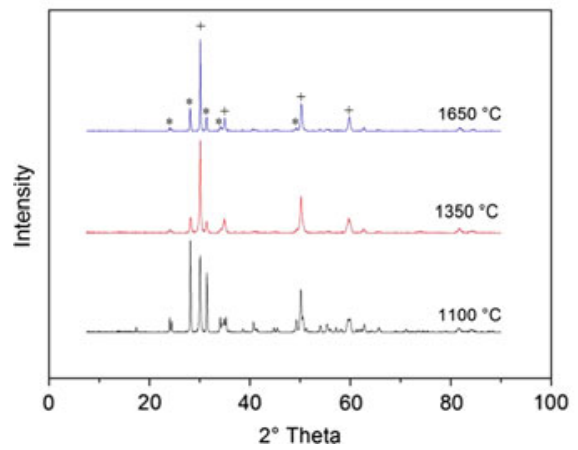

(b)

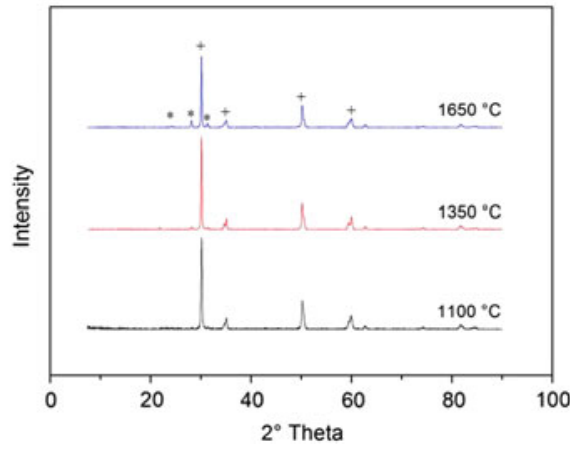

Fig. 1.32 X-ray diffraction patterns of the yttria-stabilized zirconia fibers as a function of the sintering conditions, a heating rate of $1 \mathrm{~K} / \mathrm{min} \mathbf{b}$ heating rate $10 \mathrm{~K} / \mathrm{min}$, (monoclinic phase indicated by *, tetragonal phase indicated by + )

(a)

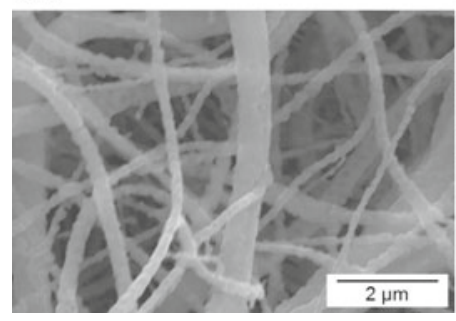

(b)

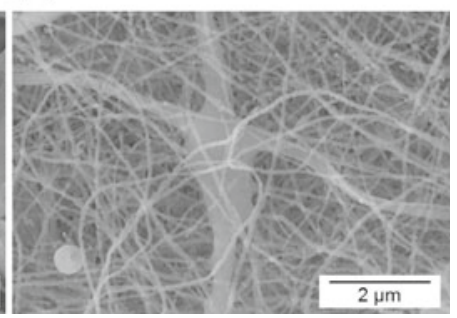

Fig. 1.33 SEM micrographs of the yttria-stabilized zirconia fibers, sintered at $1100{ }^{\circ} \mathrm{C}$ with a heating rate of $\mathbf{a} 1 \mathrm{~K} / \mathrm{min}$ and $\mathbf{b} 10 \mathrm{~K} / \mathrm{min}$ 
(a)

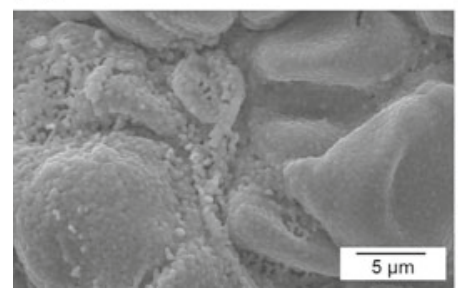

(b)

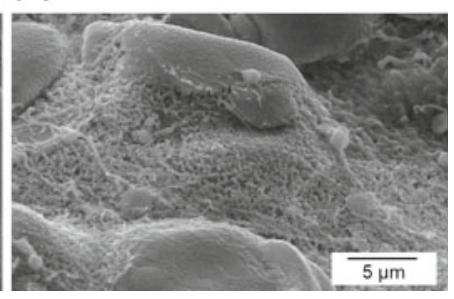

Fig. 1.34 SEM micrographs of the yttria-stabilized zirconia fibers, sintered at $1350{ }^{\circ} \mathrm{C}$ with a heating rate of a $1 \mathrm{~K} / \mathrm{min}$ and $\mathbf{b} 10 \mathrm{~K} / \mathrm{min}$

\subsection{Summary}

The present work focused on the development of metal matrix composites and ceramic matrix composites using innovative casting technologies that are typically employed for the fabrication of ceramic components.

The ceramic processing route of polyurethane foams at room temperature has been applied for the development of open cell foam structures based on austenitic stainless TRIP-steel and TRIP-steel/zirconia composite materials. Advantages have been achieved in terms of higher compressive stresses as well as energy absorption during deformation. Particularly, the supplement of the TRIP-matrix composite with a dense coating (jacket) at the foam macrostructures led to a light structure design with excellent energy absorption values. Due to EBSD-analysis the stress-induced martensitic phase transformation of metastable tetragonal zirconia has been identified at compressive strains below $2 \%$.

Full and hollow beads based on austenitic stainless TRIP-steel have been developed using the gel casting technology. A major success was the development of functionally graded beads prepared via gel casting in combination with a specific heat treatment. The developed full beads (composition 10Z) as well as the functionally graded beads have compressive strengths of approx. $380 \mathrm{MPa}$ at a compression of $15 \%$. The pure metal reference material $(0 \mathrm{Z})$ shows a significantly lower strength of $150 \mathrm{MPa}$ at the same compression. At about $15 \%$ compression the full TRIPmatrix beads collapse. The functionally graded beads have a good integrity up to $30 \%$ compression and have a significantly higher strength. At small deformation, the stress level of macroscopic bead structures is well above single beads, but then fails due to the poor joining strength. Therefore, the joining between the beads should be optimized to combine the properties of the particle-reinforced beads and functionally graded beads with the good properties of the spherical macrostructures. The functionally graded beads as well as the particle-reinforced beads with 5 and 10 vol.\% zirconia show greatest potential within the group of metal beads obtained by gel casting in terms of energy absorption. 
Paper-derived metal matrix composites have been developed using the papermanufacturing technology. Initially sintered TRIP-matrix composites were characterized by a strong carbide formation, resulting in a brittle fracture behavior of these materials. The crack initiation always started from the precipitates and the cracks propagated along the grain boundaries. The highest tensile strength was determined for the zirconia-free reference material with $177 \mathrm{MPa}$ at a total porosity of $66 \%$. A further sintering approach concerned the purification of the flushing gas Argon 5.0 and the improvement of the sealing performance of the furnace. As a result the formation of carbide precipitations was prevented. In a further development, cellulose pulp fibers have been successfully replaced by commercially available zirconia fibers. The resulting fiber reinforced TRIP-matrix composites showed improved tensile strength of $207 \mathrm{MPa}$, which was approx. 33\% higher than for the zirconia-free reference material at a significantly lower porosity. The easy casting technology of the paper-derived metal matrix composites, the possibility to tune the functional properties as well as the raw material selection allows a wide range of applications e.g. as filter material, heat exchanger or catalyst material.

Open cell foam structures based on magnesia partially stabilized zirconia were prepared using the replica technique. If the spray coating procedure was done airstream assisted the homogeneity of the ceramic struts was significantly improved. The optimized slurry based on magnesia partially stabilized zirconia contained $45 \mathrm{wt}$. \% water. After the infiltration of the sintered foam structures the TRIP-matrix composite contained $4.5 \mathrm{vol} . \%$ monoclinic zirconia, $49.8 \mathrm{vol} \% \%$ tetragonal zirconia and $45.7 \mathrm{vol} . \%$ cubic zirconia. Thus, approximately $50 \mathrm{vol} . \%$ of the ceramic material is able to transform stress-assisted. The steel matrix consisted of $100 \%$ austenite.

Another emphasis of the present work was the fabrication of ceramic matrix composites using pressure slip casting. After successful casting the composites were sintered at $1550{ }^{\circ} \mathrm{C}$ in argon atmosphere and the homogenous distribution of the steel particles within the matrix materials has been verified. As a result of the casting technology and the sintering temperatures the pressure slip casted ceramic matrix composites had open porosities of $\geq 27 \%$. Within this work package the wear behavior of the composites has been investigated using a pin-on-disc test. The wear behavior of the pressure slip casted composites was similar to existing results in literature and will be improved if the sintering parameters are optimized. Moreover, the pressure slip casted ceramic matrix composites have a high potential for applications at elevated temperatures, since they show a good resistance to thermal shock [16].

A further challenge was the development of zirconia fibers with a tailored phase composition via electrospinning. Fibers were successfully prepared from polyvinylpyrrolidone (PVP), $\mathrm{ZrOCl}_{2} \cdot 8 \mathrm{H}_{2} \mathrm{O}$ and $\mathrm{Y}\left(\mathrm{NO}_{3}\right)_{3} \cdot 6 \mathrm{H}_{2} \mathrm{O}$. Up to a sintering temperature of $1100{ }^{\circ} \mathrm{C}$ single zirconia fibers can be obtained. Due to the addition of varying amounts of yttrium (III) nitrate hexahydrate the phase composition was successfully tailored.

Acknowledgements The authors gratefully acknowledge the financial support of the Deutsche Forschungsgemeinschaft (DFG, German Research Foundation) for funding this research project A1 
within the frame of the Collaborative Research Center (CRC) 799-TRIP-Matrix-Compositesproject number 54473466 .

We would like to thank our former colleagues Dr.-Ing. Wolfgang Schärfl and Dipl.-Ing. Manuel Hasterok for their contribution to the subproject A1. For the experimental support we would like to acknowledge the support of Dipl.-Ing. Anna Schneider and M.Sc. Christian Krumbiegel. Moreover, we like to thank our colleagues of the CRC 799, particularly Dr.-Ing. Anja Weidner, Dr.-Ing. Anke Dalke, Dr.-Ing. Katja Pranke and Dipl.-Ing. Christine Baumgart. We greatly appreciate the support of our colleagues at the Chair of Ceramics, in particular Dr.-Ing. Christian Weigelt, Dr.-Ing. habil. Harry Berek, Dr.-Ing Christiane Biermann and M.Eng. Ashish Pokhrel.

\section{References}

1. C. Aneziris, W. Schärfl, H. Biermann, U. Martin, Int. J. Appl. Ceram. 6, 727 (2009)

2. C.G. Aneziris, H. Biermann, P. Scheller, TU Bergakademie Freiberg, German Patent, DE10 2007044 160, 19 June 2008

3. C.G. Aneziris, H. Berek, M. Hasterok, H. Biermann, S. Wolf, L. Krüger, Adv. Eng. Mater. 12, $197(2010)$

4. M. Oppelt, C. Wenzel, C.G. Aneziris, H. Berek, Metall. Mater. Trans. B. 45, 2000 (2014)

5. M. Oppelt, C.G. Aneziris, J. Alloys. Compd. 634, 43 (2015)

6. M. Oppelt, T. Leißner, H. Berek, C. Baumgart, L. Krüger, U. Peuker, C.G. Aneziris, Adv. Eng. Mater. 21, 1 (2018)

7. M. Oppelt, Dissertation, Technische Universität Bergakademie Freiberg (2018)

8. C. Wenzel, Dissertation, Technische Universität Bergakademie Freiberg (2016)

9. M. Hasterok, C. Wenzel, C.G. Aneziris, U. Ballaschk, H. Berek, Steel Res. Int. 82, 1032 (2011)

10. C. Wenzel, C.G. Aneziris, Steel Res. Int. 82, 1057 (2011)

11. W. Schärfl, H. Berek, C.G. Aneziris, M. Weider, A. Yanina, Adv. Eng. Mater. 13, 480 (2011)

12. M. Weider, K. Eigenfeld, Steel Res. Int. 82, 1064 (2011)

13. G.C. Jacob, J.F. Fellers, S. Simunovic, J.M. Starbuck, J. Compos. Mater. 36, 813 (2002)

14. H. Berek, C.G. Aneziris, M. Hasterok, H. Biermann, S. Wolf, L. Krüger, Solid State Phenom. 172-174, 709 (2011)

15. C. Wenzel, C.G. Aneziris, K. Pranke, Metall. Mater. Trans. A. 47, 160 (2016)

16. C. Wenzel, C. G. Aneziris, Mater. Sci. Eng., B 176, 32 (2011)

17. H. Berek, C.G. Aneziris, M. Hasterok, H. Biermann, S. Wolf, L. Krüger, Adv. Eng. Mater. 13, 1037 (2011)

18. C.G. Aneziris, W. Schärfl, TU Bergakademie Freiberg, German Patent, DE10 2007001724 A1, 11 July 2008

19. C. Weigelt, Dissertation, Technische Universität Bergakademie Freiberg (2013)

20. J.S. Reed, Principles of Ceramic Processing, 2nd edn. (Wiley, New York, 1995)

21. E. Davies, A. Lowe, J. Am. Ceram. Soc. 91, 1115 (2008) 
Open Access This chapter is licensed under the terms of the Creative Commons Attribution 4.0 International License (http://creativecommons.org/licenses/by/4.0/), which permits use, sharing, adaptation, distribution and reproduction in any medium or format, as long as you give appropriate credit to the original author(s) and the source, provide a link to the Creative Commons license and indicate if changes were made.

The images or other third party material in this chapter are included in the chapter's Creative Commons license, unless indicated otherwise in a credit line to the material. If material is not included in the chapter's Creative Commons license and your intended use is not permitted by statutory regulation or exceeds the permitted use, you will need to obtain permission directly from the copyright holder.

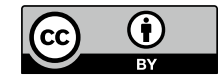

